\title{
LEAGILE SUPPLY CHAIN NETWORK DESIGN THROUGH A DYNAMIC TWO-PHASE OPTIMIZATION IN VIEW OF ORDER PENETRATION POINT
}

\author{
Masoud Rabbani ${ }^{1, *}$, Soroush Aghamohamadi-Bosjin ${ }^{1}$ And Neda Manavizadeh ${ }^{2}$
}

\begin{abstract}
In the contemporary world, combining the concept of agile and lean manufacturing (LM) is one of the most strategic and appealing concerns in the industrial environments. In this paper, a new Leagile structure is proposed for a supply chain. This research covers long term and mid-term horizon by designing a supply chain network up to the order penetration point (OPP) and final assembly and sale planning respectively. The problem is programmed in two phases. First, a bi-objective optimization is developed to minimize the total cost related with LM. In the second phase, the total cost and the customer service level (CSL) are considered as the agile manufacturing (AM) architecture. In the proposed model, a utility function is applied to set balance between the price and customer satisfaction. In addition, a robust credibility-based fuzzy programming (RCFP) is developed to handle uncertainty of the first phase. The proposed model and the solution method are implemented for a real industrial case study to show the applicability and usefulness of this study. According to the results, improving the customer service level can enhance the total cost of the second phase meaning that customer responsiveness price is too high for the proposed system.
\end{abstract}

Mathematics Subject Classification. 90B06.

Received July 6, 2019. Accepted April 22, 2020.

\section{INTRODUCTION}

Lean manufacturing (LM) and Agile manufacturing (AM) are the prevalent concerns for the companies which consider the development in the profit and the market uptake aspects. The main goal of lean concept is to eliminate non-added value activities and the main goal of agility is to use market knowledge and a virtual corporation to exploit profitable opportunities in a volatile market place. In other words, AM calls for a high level of rapid reconfiguration but does not emphasize on the elimination of all wastes as a prerequisite, while LM states that all non-value adding activities (Muda) must be eliminated. Leagility is composed of two earlier concepts; leanness and agility, in organization frameworks. It has been noted that a Leagile supply chain (LSC) can have two kinds of products: functional (related to leanness), and innovative (related to agility attributes) [41]. It is financially advised to deal with innovative products with agile standpoint and functional or common products using lean policy [41]. One of the main requirements of combining lean and agile patterns is the accurate location of OPP in the SC [27], especially in manufacturing segment because it is more suitable that

Keywords. Leagile manufacturing, supply chain network design, order penetration point, robust optimization, credibility measure.

1 School of Industrial Engineering, College of Engineering, University of Tehran, Tehran, Iran.

2 Department of Industrial Engineering, Khatam University, Tehran, Iran.

* Corresponding author: mrabani@ut.ac.ir 
focus on unpredictable and new order-driven demands which need to reconfigure product offers, in downward chain until OPP and concentrate on balancing resource usage level $[14,29]$ in upward chain until OPP through make-to-stock strategy to response a prediction. Aforesaid concept in recent worked quantifications has not been considered while is necessary for leagile architecture configuration. As a result, leagility is required to be implemented in order to respond to an uncertain demand of the economic market segments and simultaneously makes it uncomplicated to facilitate level scheduling and balance the resource stream [11]. In this study, to handle uncertainty, a robust optimization approach is applied whereas unreliable data has been considered as possibilistic parameters. This risk-averse approach (robust optimization) is recommended to handle risky strategies like agility $[12,35]$. Robust possibilistic programming is presented by Pishvaee et al. [32]. In this regard, the main contributions of the current study are presented is follows:

- Proposing a two-phase lean-agile multi objective model for a supply chain system.

- Applying a utility function to set a balance between the expectations of the customer, quality and price of the products.

- Designing a new objective function to enhance the responsiveness of the system.

- Applying a robust credibility-based fuzzy programming approach the deal with uncertainty of the model.

- Applying the proposed model in a real case to show the applicability of the model.

The rest of paper accomplished following sections. In Section 2, literature of LSC is reviewed. In Sections 3 and 4, the problem and new contributed assumptions and convenient formulations are described, respectively. In Section 5, RCFP is proposed and is used for programming discussed model in Section 4. In Section 6, solution approach is explained step by step to gain optimal desired output. Proposed leagile structure, modeling and solution method are implemented for SC of real industrial case study which produces radio equipment and television transmitters, in Section 7. And finally, conclusion of the study and some future research directions is stated in Section 8.

\section{Literature REVIEW}

There are different studies considering various features of supply chain in recent years $[12,21,35,39]$. Delivery time, quality and waste removal are the leanness's main criterion and delivery time and service level is the main criteria of agility. Raj et al. [33] developed a conceptual model for agile production system using graph theory to calculate the relationship between the agile enablers and criteria and attributes in top-down way. El Mokadem [10] compared the AM and LM production strategies in supplier selection criteria. Haq and Boddu [15] aimed to determine the most appropriate enablers for leagile supply chains by considering the features of market in a competitiveness situation. Agile customer response adoption and customization are part of criteria set, which they have defined. Lim et al. [22] developed a novel model to consider agility features and quick response to costumers beside traditional costs in supply chain location problems. Gössinger and Kalkowski [13] used a capable to promise approach in order to increase the responsiveness against costumers and anticipated the delivery dates to decrease the violations of promises. Flexibility is one of the most important factors in an agile supply chain, flexibility can be divided into different branches. Jakubovskis [18] presented a model to compare dedicated and flexible capacities in a production system with uncertain demands and showed increasing the proportion of flexible capacity can increase capacity utilization. Study of OPP is one of main issue in this field which is checked out in works such as Faiza [11]. Zhang et al. [41] believed that production before OPP is appropriate for stock-driven production and low-swing up the use of the resources and after that is right to be flexible with volatile demands. Different policies of transportation can be related with the demand rate of products which can take into account in AM and LM production systems as an integrated model based on Sağlam and Banerjee [34] research. Customer and market sensitivity have been known as one of original tools to achieve a LSC by several works such as Vinodh and Aravindraj [38], Faiza [11] and Carvalho et al. [7], especially in the volatile markets that attracting and keeping customers requires agile product customization $[12,35]$. The alliance within organization and commonwealth companies (visual organization) is considered by 
Pan and Nagi [29] that is one of productive strategic solution to manage the lack of lifetime of products. In this regard, Carvalho et al. [7] considered agility that emphasizes the formation of virtual organization and trade agilely among the central organization and other members and distributors. Brusset [6] provided a framework about the agility in supply chain and described how inter-organizational work can increase the agility in supply chain. Naim and Gosling [27] had more emphasis on the final assembly.

The Build-to-Order (BTO) strategy is used for MTS and MTO strategy combination which are the most appropriate for LM and AM respectively. Lin and Wang [23] designed a BTO SC network that included two type of manufacturing process: producing semi-fabricated modules and assembling them and making final products. Hum et al. [16] considered a network structure for a supply chain and proved that supply chains are involved with queue systems and defined Supply chain responsiveness as the probability of fulfilment costumer orders within a specific period which is mostly related with an agile supply chain. Yimer and Damirli [40] applied BTO strategy to the SC in environments with high demand diversity for agile product customization. Beemsterboer et al. [3] explained the advantages of considering a hybrid MTS and MTO system in a production planning. Beemsterboer et al. [4] used Markov Decision Process Modeling to optimize the amount of lot size in a hybrid MTS and MTO system in order to increase the flexibility of system for various rate of demands. Pan and Nagi [29] tried to manage cost variability due to the uncertainty of demands, and this was another element in the cost OF. Hasani et al. [14] developed a model to act agilely in providing and collecting perishable products as a measure for AM in closed-loop SC of perishable goods. Babazadeh et al. [2] adhered to some principles of agility in SC, such as the ability to send the goods directly from factories, forming a virtual organization and decreasing customer waiting time. Chan and Kumar [8] proposed a scheduling plan in tactical level in compliance with the leagile principles to reduce time muda (waiting time) and to shorten delivery time. Liu et al. [25] developed a novel NSGA-II method to optimize energy consumption as a waste by employing intelligence scheduling methods. Nieuwenhuis and Katsifou [28] described the relation between leagile systems and sustainability, in other word overproduction of products lead to more resource consumption which is against the green objectives. Companies who implement project-oriented production by scheduling and resource decisions in the MTO context will be successful. Like Li and Womer [20], the current study takes into account the project-oriented companies. In this regard, the proposed model applies in terms of the MTO strategy for agile side. Aghamohamadi-bosjin et al. [1] developed an agile lot sizing and scheduling model, they aimed to design a quick to response model in order to enhance the agility of the model and applied a new hybrid metaheuristic algorithm to solve the problem. Khan et al. [19] proposed a seller-buyer supply chain system in which the demand was uncertain. They showed that causing pauses in shipment lead time can increase the number of transported items to avoid shortages. Taleizadeh et al. [36] considered a system with two markets and a manufacturer in which the manufacturer offers different prices or the markets. They assessed the effect of different strategies on the willing to pay of the markets. According to the prementioned articles, considering the role of utility function to make balance between price and quality, considering the responsiveness as a new objective function in a lean-agile supply chain system, proposing a two-phase lean-agile supply chain system are the main research gaps and the current study aims to cover these research gaps.

\section{Problem Description}

In this paper, the subjected SC problem is considered as a pseudo-hierarchical two-phase problem which takes into account new procurement planning in phase II that is not planned in phase I. Figure 1, illustrates the considered SC network and OPP location. In stage one, demands data is assumed possibilistic parameters which is acquired by prediction. Lost is not being considered in the assumptions, because, satisfaction and capacity constraints are highlighted with robust optimization to cover all predictions. At the second phase, demands are crisp. Usually LSC is suitable for electrical products as well as food industry [26]. 


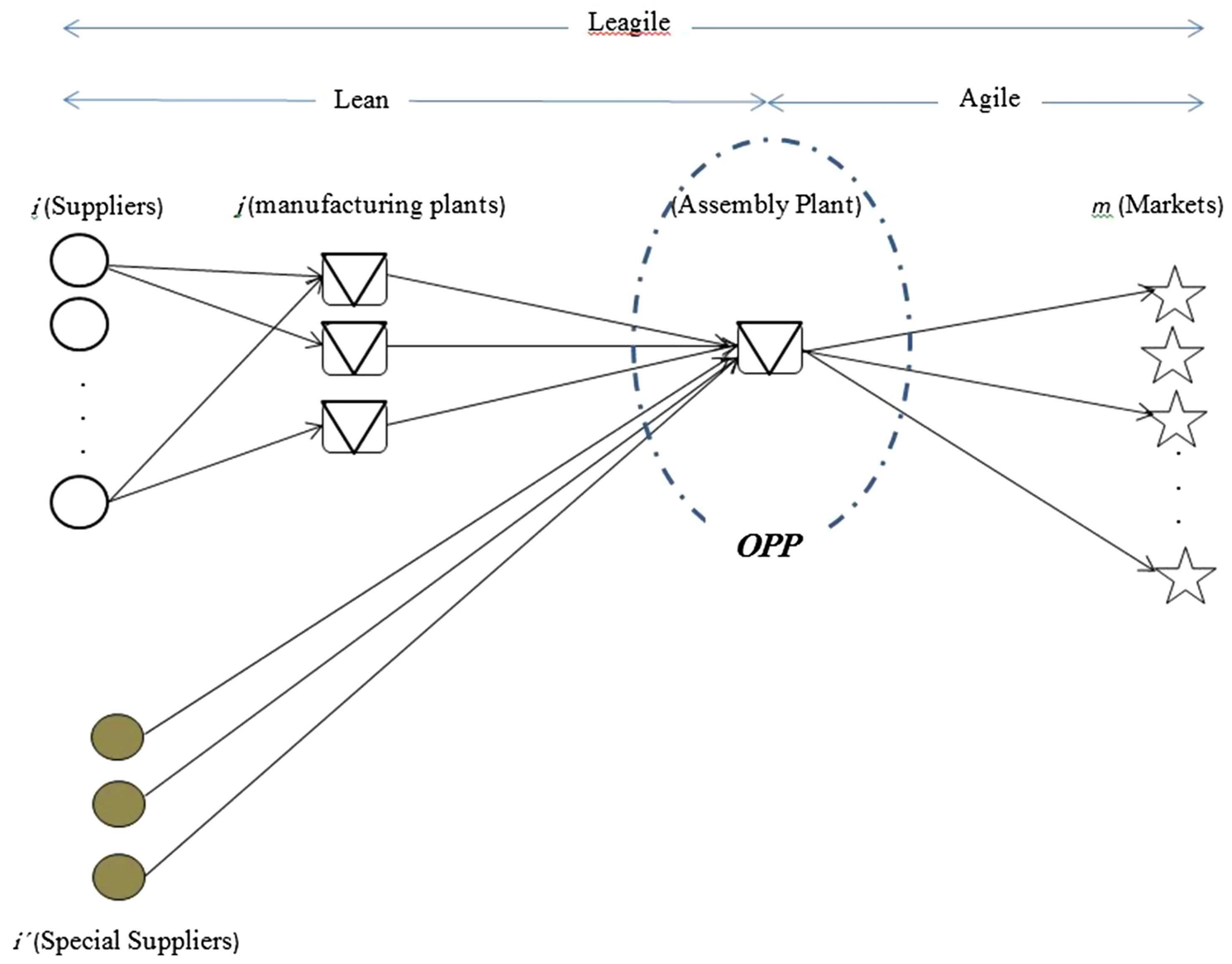

FiguRE 1. General schema for LSC configuration.

As shown in Figure 2, this problem is comprised of some specific assumptions as follows:

- At lean plan, it is assumed that the raw materials and produced items are available as inventory from the the beginning of the period which means excessive items are being held as inventory in the future periods of time. In this respect, the prepared products are ready to be shipped to the assembly center when it is necessary (see [1] for additional research bout inventory system).

- In the first phase, the planning horizon is one year with monthly courses and in the second phase, the planning horizon is seasonal with weekly periods.

- The innovative products through customer design are consisted of a common board and a series of specific elements, which have been formed by assembling in final assembly.

- Special elements for the innovative products, are bought from certain dealers after releasing orders that could be stored after purchasing. But, in this case, we have the risk of obsolescence, which after 10 periods (weeks) material obsolescence costs exponentially increase during the periods. Obsolescence cost at eleventh period, after the purchase, is equivalent to $50 \%$ of their holding cost and increases exponentially in the later periods. Formula (3.1) describes how to calculate that, $h$ shows the difference in the number of periods between the purchase and utilization, $T^{\prime}$ is the planning horizon at the second phase. Due to the fact that adding any number of periods in the difference between purchase and consumption periods, the expenditure increased by $50 \%$, formula (3.2) calculates used at formula (3.1). 


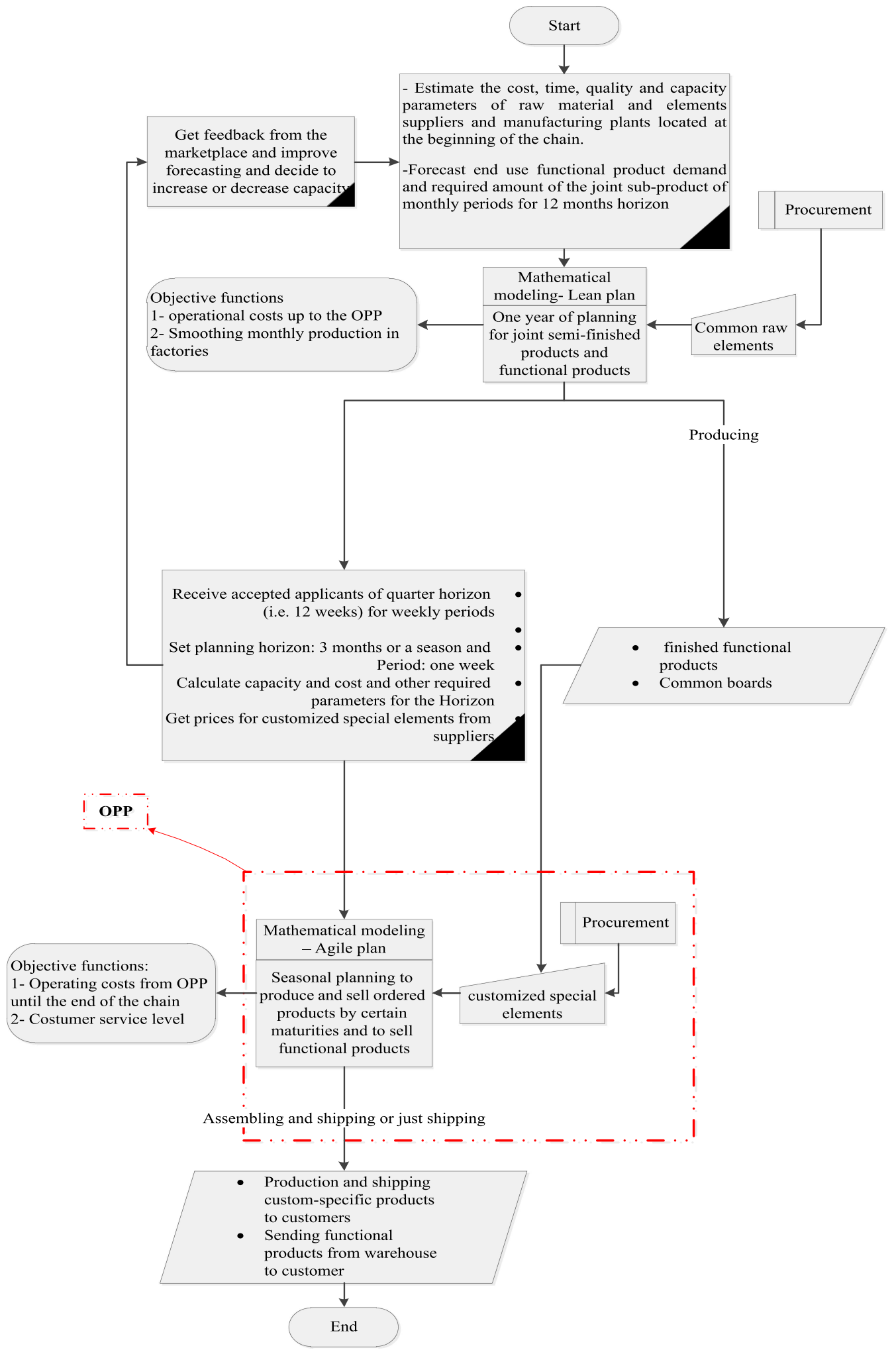

FIgURE 2. The proposed decision support system for LSC planning. 


$$
\begin{aligned}
& \begin{cases}\operatorname{ch}_{s t^{\prime}}^{d}=\left(\operatorname{ch}_{s t^{\prime}}^{d}\right)^{\frac{h}{\phi_{k s t^{\prime}}^{d}}}, h \in\left\{10,11, \ldots, T^{\prime}-1\right\} & \text { if } t^{\prime} \geq s+10 \\
\operatorname{ch}_{s t^{\prime}}^{d}=\operatorname{ch}_{s t^{\prime}}^{d} & \text { O.W. }\end{cases} \\
& \begin{cases}\operatorname{ch}_{s t^{\prime}}^{e}=\left(\operatorname{ch}_{s t^{\prime}}^{e}\right)^{\frac{h}{\phi_{s t^{\prime}}^{e}}}, h \in\left\{10,11, \ldots, T^{\prime}-1\right\} & \text { if } t^{\prime} \geq s+10 \\
\operatorname{ch}_{s t^{\prime}}^{e}=\operatorname{ch}_{s t^{\prime}}^{e} & \text { O.W. }\end{cases} \\
& \phi_{s t^{\prime}}^{d}=\frac{3}{1+\log _{\operatorname{ch}_{s t^{\prime}}^{1.5}}^{d}} .
\end{aligned}
$$

- If requested access to certain materials and elements with good quality is not available, cheaper elements could be used to be replaced in the product, in which case, lost penalty does not occur but, costs, such as failure to satisfy customer expected utility will occur. If cheaper elements, according to customer wishes, is not available, better quality parts can be replaced. Therefore, rising costs and customer dissatisfaction of such situation, will occur.

- Final assembly includes assembly of low-end products that is produced by assembling cheap specified elements and high-end products which is produced by assembling more expensive ones.

In phase II, as a penalty from replacement to respond customer (cheap rather than expensive or vice versa) for each alternated product offered to each customer in each period, the amount of calculated charge by formula (3.3) is added to $\mathrm{TC}^{2 \mathrm{nd}}$ and also, if the replacement is happened as follows, low-end rather than high-end and vice versa, the CSL OF would be deducted as much as the values calculated by formula (3.4) and (3.5), respectively.

$$
\begin{array}{r}
c_{g n t}^{d, e} \times \frac{S^{d, e}}{\gamma_{g}^{e}} \\
\frac{\left(\mathrm{util}_{g m}^{\mathrm{H}}-\mathrm{util}_{g m}^{\mathrm{L}}\right)}{\mathrm{util}{ }_{g m}^{\mathrm{H}}} \times \frac{S_{g t^{\prime}}^{e, d}}{\gamma_{g}^{d}} \\
\frac{\left(\operatorname{pr}_{g}^{\mathrm{H}}-\operatorname{pr}_{g}^{\mathrm{L}}\right)}{\operatorname{pr}_{g}^{\mathrm{L}}} \times \frac{S_{g t^{\prime}}^{d, e}}{\gamma_{g}^{e}}
\end{array}
$$

Accountability penalty for substituting a cheaper alternative to a more expensive unit is equivalent to: final price difference between expensive and cheap products, minus the difference between the utility of expensive and cheaper goods for customers (3.6).

$$
c_{g m}^{d, e}=\left(\operatorname{pr}_{g}^{\mathrm{H}}-\operatorname{pr}_{g}^{\mathrm{L}}\right)-\left(\mathrm{util}_{g m}^{\mathrm{H}}-\mathrm{util}_{g m}^{\mathrm{L}}\right) .
$$

In order to obtain values for the parameters associated with the desirability of the product for the customer, the utility function given by Ding et al. [9], is applied:

$$
\mathrm{util}_{g m}^{\mathrm{H} / \mathrm{L}}=\frac{e^{\beta_{g m}^{\mathrm{H} / \mathrm{L}}\left(\mathrm{pr}_{g}^{\mathrm{H} / \mathrm{L}}-\chi_{m g}^{\mathrm{H} / \mathrm{L}}\right)}}{\alpha_{g m}^{\mathrm{H} / \mathrm{L}}+e^{\beta_{g m}^{\mathrm{H} / \mathrm{L}}}\left(\operatorname{pr}_{g}^{\mathrm{H} / \mathrm{L}}-\chi_{m g}^{\mathrm{H} / \mathrm{L}}\right)} \times V_{g}^{\mathrm{H} / \mathrm{L}}-\mathrm{pr}_{g}^{\mathrm{H} / \mathrm{L}} .
$$

Note that the coefficient $\beta_{g m}^{\mathrm{H} / \mathrm{L}}$ is the quality information of product $g$ in a way that increasing product price increases the product quality in the client view, and therefore, it would be equal to zero, if the customer perceived quality is not directly related to the price. Coefficient $\alpha_{g m}^{\mathrm{H} / \mathrm{L}}$ is the quality of product $g$ for the customer $m$ whereas the same-quality product for the customer with higher $\alpha_{g m}^{\mathrm{H} / \mathrm{L}}$, is less favorable relative to the customer who has a lower $\alpha_{g m}^{\mathrm{H} / \mathrm{L}}$. Coefficient $V_{g}^{\mathrm{H} / \mathrm{L}}$ equals to the maximum amount of utility among the customers when the product $g$ unlimitedly has the highest quality. Coefficient $\chi_{g m}^{\mathrm{H} / \mathrm{L}}$ is the price of product $g$ that customer $m$ expects. 


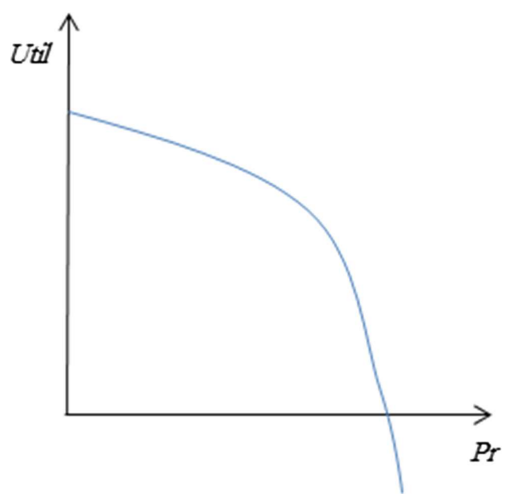

FiguRE 3. Graphic representation of utility for a given price.

These values are provided by the marketing department, and the utility of the products is calculated based on a function of price and aforesaid default values. Usually concerned products in our problem are of kinds which the behavior of their utility is as follows in Figure 3, because according to specifications of customized products, lower prices increases desirability for the consumers. And in this downward trend, usually extremely low price would not make the customers to suspect product quality and reduce utility. This behavior is called Bargain hunter proposed by Ding et al. [9], which is applicably valid for cases with following values:

$$
\beta_{g m}^{\mathrm{H} / \mathrm{L}} \leq 4 / V_{g}^{\mathrm{H} / \mathrm{L}} \quad \text { or } \quad \beta_{g m}^{\mathrm{H} / \mathrm{L}}>4 / V_{g}^{\mathrm{H} / \mathrm{L}} \cap \alpha_{g m}^{\mathrm{H} / \mathrm{L}} \in\left(0, e^{-\beta_{g m}^{\mathrm{H} / \mathrm{L}} \chi_{m g}^{\mathrm{H} / \mathrm{L}}}\right) .
$$

\section{Proposed mathematical modeling}

\subsection{Phase I (Lean plan)}

The mathematical model presented in this subsystem determines optimal outsource and production quantity for joint sub-products and functional products which are Agile-phase input data.

$$
\begin{aligned}
\text { Min } \mathrm{TC}^{1 \mathrm{nd}}= & \sum_{t} \sum_{i} \sum_{r} \mathrm{oc}_{i r t} O_{i r t}+\sum_{t} \sum_{i} \sum_{j}\left[\sum_{r} c_{i r}^{c} X_{i j r t}^{c}\right]+\sum_{t} \sum_{i} \sum_{j}\left[\mathrm{ct}_{i j}^{c} \sum_{r} X_{i j r t}^{c}\right] \\
& +\sum_{t} \sum_{j}\left[\mathrm{cp}_{j f}^{F} \sum_{f} Y_{j f t}^{F}+\mathrm{cp}_{j}^{C} Y_{j t}^{C}\right]+\sum_{t} \sum_{j}\left[\sum_{f} \mathrm{ct}_{j f}^{F} Y_{j f t}^{F}+\mathrm{ct}_{j}^{C} Y_{j t}^{C}\right] \\
& +\sum_{t} \sum_{j}\left[\sum_{r} \mathrm{ch}_{j r}^{c} I_{j r t}^{c}\right]+\sum_{j} \sum_{t} \operatorname{co}^{C} \mathrm{OS}_{j t}^{C}+\sum_{j} \sum_{t} \sum_{f} \operatorname{co}_{f}^{F} \mathrm{OS}_{j f t}^{F} \\
\operatorname{Min} \operatorname{MRUBF}_{=} & \frac{\sum_{j} \mathrm{RUBF}_{j}}{|J|} \\
\operatorname{RUBF}_{j}= & \frac{\sum_{t}\left|\left(\frac{\sum_{f} Y_{j f t}^{F}+Y_{j t}^{C}}{\operatorname{Cap}_{j}}\right)-\left(\frac{\sum_{f} \sum_{t} Y_{j f t}^{F}+\sum_{t} Y_{j t}^{C}}{|T| \mathrm{Cap}_{j}}\right)\right|}{|T|} \\
\sum_{j} \mathrm{OS}_{j t}^{C}+\sum_{j} Y_{j t}^{C} \geq & \operatorname{need}_{t}^{C}
\end{aligned}
$$




$$
\begin{aligned}
& \sum_{j} \mathrm{OS}_{j f t}^{F}+\sum_{j} Y_{j f t}^{F} \geq \operatorname{dem}_{f t}^{F} \\
& \sum_{i}\left(1-\mathrm{DR}_{i r}^{C}\right) X_{i j r t}^{C}+I_{j r, t-1}^{C}=I_{j r t}^{C}+\gamma_{r}^{C} Y_{j t}^{C}+\gamma_{r}^{F} \sum_{f} Y_{j f t}^{F} \quad \forall j, r, t \\
& O_{i r t} \mathrm{SC}_{i r}^{C_{-} M i n} \leq \sum_{j} X_{i j r t}^{C} \leq O_{i r t} \mathrm{SC}_{i r}^{C-M a x} \quad \forall i, r, t \\
& \sum_{r} \sum_{i} u v_{r}^{C}\left(X_{i j r t}^{C}+I_{j r, t-1}^{C}\right) \leq \mathrm{WS}_{j}^{\mathrm{L}} \quad \forall j, t \\
& Y_{j t}^{C}+\sum_{f} Y_{j f t}^{F} \leq \operatorname{Cap}_{j} \quad \forall j, t \\
& I_{j r t}^{C} \geq \mathrm{Ss}_{j r t}^{C} \quad \forall j, r, t \\
& \mathrm{OS}_{j t}^{C}+Y_{j t}^{C}=Q_{j t}^{C} \quad \forall j, t \\
& \mathrm{OS}_{j f t}^{F}+Y_{j f t}^{F}=Q_{j f t}^{F} \quad \forall j, f, t .
\end{aligned}
$$

In the first phase, In order to achieve a lean purchase plan, purchases parameters are critical and for the cases greater than their threshold, their suppliers are not chosen to trade.

$$
\begin{cases}c_{i r}^{c}=M & \text { if } \mathrm{dr}_{i r}^{C} \geq \overline{\mathrm{DR}}_{r}^{C} \quad \cup \mathrm{dt}_{i r}^{C} \geq \overline{\mathrm{DT}}_{r}^{C} \\ c_{i r}^{c}=c_{i r}^{c} & \text { O.W. }\end{cases}
$$

Equation (4.1) shows operational costs up to OPP which includes procurement fixed and variable costs like contract dealing and purchasing costs, transportation costs and other costs such as productions, raw elements holding - note that production center has only raw material storage -, and outsourcing. Equation (4.2) presents second OF which minimize expected resource usage balance factor (RUBF) in production sites that defined in equation (4.3). Equation (4.3) presents mean absolute error (MAE) for production divided by capacity in time periods. This OF decreases fluctuation in production in periods. Expression (4.4), ensures that the required common boards are manufactured and outsourced at a rate that is estimated. This value is calculated by equation (4.14) using the predicted demand for customized (Innovative) products.

$$
\operatorname{need}_{t}^{C}=\sum_{g} \sum_{m} \gamma_{g}^{C} \operatorname{dem}_{g m t}^{\mathrm{In}}
$$

Inequality (4.5) warrants functional products to satisfy the anticipated demand. Equation (4.6) establishes dynamic balance between inventory and purchasing redeemable parts and production amount. Expression (4.7) ensures the amount of purchases from suppliers not to exceed preparation capacity and minimum allowable quantity. Expression (4.8) ensures dynamically at any time to have entrance up to the amount of space is available in the warehouse. Expression (4.9) ensures that the amount of output per period not to exceed the fixed capacity of each site. Inequality (4.10) shows that available inventory of purchased parts should be at least as much as safety stock. Equations (4.11) and (4.12) calculate amount of produced or outsourced functional and semi-finished products which is applied as input for model of second phase.

\subsection{Phase II (Agile plan)}

In this sub-system, as expected, the variability of demands should be answered agilely with appropriate service levels, therefore, having regard to the penalty fee resulted by failing to meet the ordered demands. Coinciding with the new fashions of volatile market is possible with refraining to buy large size of parts as well as long-time storage in which eventually becomes obsolete. For this purpose, the two-time indices are taken into account as the following, it is assumed an index $(s)$ as the period of the purchase and an index $\left(t^{\prime}\right)$ as the period of 
assembly.

$$
\begin{aligned}
& \min \mathrm{TC}^{2 \mathrm{nd}}=\sum_{i^{\prime}} \mathrm{FcA}_{i^{\prime}} \mathrm{AL}_{i^{\prime}}+\sum_{s}^{t^{\prime}} \sum_{t^{\prime}}\left(\operatorname{ch}_{s t^{\prime}}^{e} I_{s t^{\prime}}^{e}+\mathrm{ch}_{s t^{\prime}}^{d} I_{s t^{\prime}}^{d}\right) \\
& +\sum_{i^{\prime}} \sum_{s}\left(c_{i^{\prime}}^{d} x_{i^{\prime} s}^{d}+c_{i^{\prime}}^{e} x_{i^{\prime} s}^{e}\right)+\sum_{i^{\prime}} \sum_{s}\left(\mathrm{ct}_{i^{\prime}}^{d} x_{i^{\prime} s}^{d}+\mathrm{ct}_{i^{\prime}}^{e} x_{i^{\prime} s}^{e}\right) \\
& +\sum_{g} \sum_{m} \sum_{t^{\prime}}\left[\left(\mathrm{cp}_{g}^{\mathrm{H}-\mathrm{In}}+\mathrm{ct}_{g m}^{\mathrm{H}-\mathrm{In}}\right) Z_{g m t^{\prime}}^{\mathrm{H}-\mathrm{In}}+\left(\mathrm{cp}_{g}^{\mathrm{L}-\mathrm{In}}+\mathrm{ct}_{g m}^{\mathrm{L}-\mathrm{In}}\right) Z_{g m t^{\prime}}^{\mathrm{L}-\mathrm{In}}\right] \\
& +\sum_{t^{\prime}}\left(\operatorname{ch}^{C} I_{t^{\prime}}^{C}+\sum_{f} \operatorname{ch}_{f}^{F} I_{f t^{\prime}}^{F}\right) \\
& +\sum_{g} \sum_{m} \sum_{t^{\prime}}\left(c_{g m}^{d, e} \times \frac{S_{g t^{\prime}}^{d, e}}{\gamma_{g}^{e}}+c_{g m}^{e, d} \times \frac{S_{g t^{\prime}}^{e, d}}{\gamma_{g}^{d}}\right) \\
& +\sum_{g} \sum_{m} \sum_{t^{\prime}}\left(\mathrm{pn}_{g m}^{\mathrm{L}-\mathrm{In}} V_{g m t^{\prime}}^{\mathrm{L}-\mathrm{In}}+\mathrm{pn}_{g m}^{\mathrm{H}-\mathrm{In}} V_{g m t^{\prime}}^{\mathrm{H}-\mathrm{In}}\right) \\
& +\sum_{f} \sum_{m} \sum_{t^{\prime}} \mathrm{pn}_{m f}^{F} V_{m f^{\prime} t}^{F}+\sum_{f} \sum_{m} \sum_{t^{\prime}} \mathrm{ct}_{f m}^{F} Z_{f m t^{\prime}}^{F} \\
& \max \mathrm{CSL}=\frac{\left(\sum_{m} \sum_{t^{\prime}} \tau_{m t^{\prime}}\right)}{\left|T^{\prime}\right||M|} \\
& \tau_{m t^{\prime}}=\frac{\sum_{g}\left(Z_{g m t^{\prime}}^{\mathrm{L}-\mathrm{In}}+Z_{g m t^{\prime}}^{\mathrm{H}-\mathrm{In}}\right)}{\sum_{g}\left(D_{g m t^{\prime}}^{\mathrm{L}-\mathrm{In}}+D_{g m t^{\prime}}^{\mathrm{H}-\mathrm{In}}\right)}-\frac{\sum_{g}\left(\frac{\left(\mathrm{utii}_{g m}^{\mathrm{H}}-\mathrm{util}_{g m}^{\mathrm{L}}\right)}{\mathrm{utii}_{g m}^{\mathrm{H}}} \times \frac{S_{g t^{\prime}}^{e, d}}{\gamma_{g}^{d}}+\frac{\left(\operatorname{pr}_{g}^{\mathrm{H}}-\mathrm{pr}_{g}^{\mathrm{L}}\right)}{\operatorname{pr}_{g}^{\mathrm{L}}} \times \frac{S_{g t^{d}}^{d, e}}{\gamma_{g}^{e}}\right)}{\sum_{g}\left(D_{g m t^{\prime}}^{\mathrm{L}-\mathrm{In}}+D_{g m t^{\prime}}^{\mathrm{H}-\mathrm{In}}\right)} \\
& Z_{g m t^{\prime}}^{\mathrm{H}-\mathrm{In}}+V_{g m t^{\prime}}^{\mathrm{H}-\mathrm{In}}=D_{g m t^{\prime}}^{\mathrm{H}-\mathrm{In}} \\
& Z_{g m t^{\prime}}^{\mathrm{L}-\mathrm{In}}+V_{g m t^{\prime}}^{\mathrm{L}-\mathrm{In}}=D_{g m t^{\prime}}^{\mathrm{L}-\mathrm{In}} \\
& Z_{m f t^{\prime}}^{F}+V_{m f t}^{F}=D_{m f t}^{F} \\
& \left\{\begin{array}{lll}
\sum_{m} Z_{m f t^{\prime}}^{F}+I_{f t^{\prime}}^{F}=I_{f, t^{\prime}-1}^{F}+\sum_{j} Q_{j f t}^{F}, & \forall t, f & t^{\prime}=4 t+1 \\
\sum_{m} Z_{m f t^{\prime}}^{F}+I_{f t^{\prime}}^{F}=I_{f, t^{\prime}-1}^{F}, & \forall t, f & t^{\prime} \neq 4 t+1
\end{array}\right. \\
& \sum_{g} \sum_{m} \gamma_{g}^{d} Z_{g m t^{\prime}}^{\mathrm{H}-\mathrm{In}}+\sum_{g} \xi^{d, e} S_{g t^{\prime}}^{d, e}=\sum_{s=1}^{t^{\prime}} I_{s t^{\prime}}^{d}+\sum_{g} \xi^{e, d} S_{g t^{\prime}}^{e, d}, \quad \forall t^{\prime} \\
& \sum_{i^{\prime}} x_{i^{\prime} s}^{d} \geq \sum_{t^{\prime}=s}^{T^{\prime}} I_{s t^{\prime}}^{d} \quad \forall s \\
& \sum_{i^{\prime}} x_{i^{\prime} s}^{e} \geq \sum_{t^{\prime}=s}^{T^{\prime}} I_{s t^{\prime}}^{e} \quad \forall s \\
& x_{i^{\prime} s}^{d}+x_{i^{\prime} s}^{e} \leq \mathrm{AL}_{i^{\prime}} M_{i^{\prime}} \quad \forall i^{\prime}, s \\
& \sum_{g} \sum_{m} \gamma_{g}^{e} Z_{g m t^{\prime}}^{\mathrm{L}-\mathrm{In}}+\sum_{g} \xi^{e, d} S_{g t^{\prime}}^{e, d}=\sum_{s=1}^{t^{\prime}} I_{s t^{\prime}}^{e}+\sum_{g} \xi^{d, e} S_{t^{\prime}}^{d, e}, \quad \forall t^{\prime} \\
& \left\{\begin{array}{lll}
\sum_{g} \sum_{m} \gamma_{g}^{c}\left(Z_{g m t^{\prime}}^{\mathrm{H}-\mathrm{In}}+Z_{g m t^{\prime}}^{\mathrm{L}-\mathrm{In}}\right)+I_{t^{\prime}}^{c}=I_{t^{\prime}-1}^{c}+\sum_{j} Q_{j t}^{c}, & \forall t, & t^{\prime}=4 t+1 \\
\sum_{g} \sum_{m} \gamma_{g}^{c}\left(Z_{g m t^{\prime}}^{\mathrm{H}-\mathrm{In}}+Z_{g m t^{\prime}}^{\mathrm{L}-\mathrm{In}}\right)+I_{t^{\prime}}^{c}=I_{t^{\prime}-1}^{c}, & \forall t, & t^{\prime} \neq 4 t+1
\end{array}\right. \\
& \sum_{m}\left(Z_{g m t^{\prime}}^{\mathrm{L}-\mathrm{In}}+Z_{g m t^{\prime}}^{\mathrm{H}-\mathrm{In}}\right) \leq \mathrm{Cap}_{g}^{\mathrm{In}}, \quad \forall g, t^{\prime} \\
& I_{t^{\prime}}^{c} \geq \mathrm{Ss}_{t^{\prime}}^{c}, \quad \forall t^{\prime}
\end{aligned}
$$




$$
I_{f t^{\prime}}^{F} \geq \operatorname{Ss}_{f t^{\prime}}^{F}, \quad \forall f, t^{\prime}
$$

Expression (4.15) shows the cost OF in phase II that minimizes the sum of the followings: fixed cost of contracts with suppliers to record orders of the season, purchasing, transportation and storage of purchased parts in the phase for final assembly and make compliance with customer requirements, holding semi-manufactured products in the warehouse, estimated costs for replacing parts, components with similar cheaper or more expensive ones and estimated costs for failing to meet the accepted demands which commonly is mentioned in contracts. Expression (4.16) represents the second OF which maximize the average level of responsiveness among customers and weeks of planning horizon, the response to any customer at any time is defined in equation (4.17). In equation (4.17), negative word shows the level of responsiveness deficits resulted from substituting high-end and low-end products, in the event, because of the replacement, differences in the relative desirability from the client sight will affect customer service levels and in vice versa, differences in the cost prices will affect customer service levels, because, $100 \%$ responsive level needs to meet $100 \%$ conformity of product with customer requirements and product price is one of the requirements. In this part, inevitably, the cost price of the product is used because pricing is not covered at the proposed structure. Equations (4.18) to (4.20) guarantee that the demand for innovative and functional products will be considered satisfied or lost. Expressions (4.21) and (4.27) warrant the dynamic balance of inventory, input and output for common boards and functional products respectively. Between phase I and phase II, there is a buffer period where, produced products at first month in phase I is regarded as input of phase II at fifth week, that is why equations (4.21) and (4.27) are applied to $t^{\prime}=4 t+1$. Equations (4.22) and (4.26) set the balance among inventory, substituted elements and their outputs. Inequalities (4.23) and (4.24) show that amount of certain components inventories purchased at period $s$ which are consumed at various periods of $T^{\prime}$ horizon is not more than inputted amount of these components at period $s$. Inequality (4.25) ensures that the components would be bought from supplier $i^{\prime}$ only if the contract is signed. The $M_{i^{\prime}}$ value is determined by equation (4.31) at least as many as the total number of parts needed to be purchased.

$$
M_{i^{\prime}} \geq \sum_{m} \sum_{g} \sum_{t^{\prime}}\left(\gamma_{g}^{d} D_{g m t^{\prime}}^{\mathrm{H}-\mathrm{In}}+\gamma_{g}^{e} D_{g m t^{\prime}}^{\mathrm{L}-\mathrm{In}}\right)
$$

Inequality (4.28) is capacity constraint. Inequalities (4.29) and (4.30) guarantee that common boards and functional products inventory should not be less than safety stock value calculated by equation (4.31), where $\lambda^{C}$ is the forward inventory coverage policy factor [37] for common boards in a way that sum of demands at previous year for same season is taken into account.

\section{UNCERTAINTY HANDLING}

\subsection{Credibility-based fuzzy programming}

In the first phase long-term planning horizon is supposed to be done, it is emphatically required to perform robust optimization and get crisp equivalent model due to the future predictions data are uncertain thus, preferably have to be considered possiblistic [30]. To explain how the distribution for the parameters could be defined see Inuiguchi et al. [17]. To simply describe RFCP, at first, the theoretical model (5.1) is considered.

$$
\begin{array}{rlrl}
\text { Min } & \text { Obj } & =\tilde{\mathbf{c}} \boldsymbol{x} \\
\text { s.t. } \quad \mathbf{A} \boldsymbol{x} & \geq \tilde{\mathbf{d}} \\
\mathbf{A}^{\prime} \boldsymbol{x} & \leq \tilde{\mathbf{c}} \\
\tilde{\mathbf{B}} \boldsymbol{x} & =\boldsymbol{y} \\
\boldsymbol{x}, \boldsymbol{y} & \geq 0 .
\end{array}
$$

Pishvaee et al. [32] developed robust possibilistic programming approach and they implemented their approach based on necessity degree. According to the model (5.2), in this study, possibilistic programming is defined 
based on credibility degree.

$$
\begin{array}{ll}
\text { Min } & E(\mathrm{Obj})=E(\tilde{\mathbf{c}}) \boldsymbol{x} \\
\text { s.t. } & \operatorname{Cr}\{\mathbf{A} \boldsymbol{x} \geq \tilde{\mathbf{d}}\} \geq \alpha \\
& \operatorname{Cr}\left\{\mathbf{A}^{\prime} \boldsymbol{x} \leq \tilde{\mathbf{c}}\right\} \geq \beta \\
& \operatorname{Cr}\{\tilde{\mathbf{B}} \boldsymbol{x}=\boldsymbol{y}\} \geq \pi \\
& \boldsymbol{x}, \boldsymbol{y} \geq 0 .
\end{array}
$$

To acquire crisp equivalent of constraints in model (5.2), delineated definitions by Liu and Liu [24] are used as follows.

Let $\tilde{a}=\left(a^{1}, a^{2}, a^{3}, a^{4}\right)$ be a trapezoidal fuzzy number and $r$ is a real number.

$$
E(\tilde{a})=\int_{0}^{\infty} \operatorname{Cr}\{\tilde{a} \geq r\} \mathrm{d} r-\int_{-\infty}^{0} \operatorname{Cr}\{\tilde{a} \leq r\} \mathrm{d} r .
$$

And since $\tilde{a}$ is supposed as a trapezoidal fuzzy number, thus $E(\tilde{a})=\left(a^{1}+a^{2}+a^{3}+a^{4}\right) / 4$, is resulted from formula (5.3a) as the expected value of $\tilde{a}$. Credibility measures are calculated such this:

$$
\operatorname{Cr}\{\tilde{a} \leq r\}=\frac{1}{2}\left(\sup _{x \leq r} \mu(x)+1-\sup _{x>r} \mu(x)\right) .
$$

If $\alpha \geq 0.5$ then we can write:

$$
\begin{aligned}
& \operatorname{Cr}\{\tilde{a} \leq r\} \geq \alpha \Leftrightarrow r \geq(2-2 \alpha) a^{3}+(2 \alpha-1) a^{4}, \\
& \operatorname{Cr}\{\tilde{a} \geq r\} \geq \alpha \Leftrightarrow r \leq(2-2 \alpha) a^{2}+(2 \alpha-1) a^{1} .
\end{aligned}
$$

Hence, we can write crisp equivalent of fuzzy chance constraints with confidence level $\alpha$.

Proposition 5.1. To get crisp equivalent of constraint $\operatorname{Cr}\{\tilde{\mathbf{B}} \boldsymbol{x}=\boldsymbol{y}\} \geq \pi$, expression (5.4) could be applied.

$$
\operatorname{Cr}\{\tilde{\mathbf{B}} \boldsymbol{x}=\boldsymbol{y}\} \geq \pi \quad \equiv \quad \mathbf{B}_{\mathbf{2}} \boldsymbol{x} \leq \boldsymbol{y} \leq \mathbf{B}_{\mathbf{3}} \boldsymbol{x}
$$

Proof. It is clear when it is asserted a fuzzy number is equal to a real number, credibility degrees of being bigger and smaller than real number are identical.

$$
\operatorname{Cr}\{\tilde{a}=r\} \geq \pi \equiv \operatorname{Cr}\{\tilde{a} \geq r\} \geq \pi / 2 \cap \operatorname{Cr}\{\tilde{a} \leq r\} \geq \pi / 2 .
$$

Also, according to expression (5.3b) the term $\operatorname{Cr}\{\tilde{a} \geq r\}=1-\operatorname{Cr}\{\tilde{a} \leq r\}$ is always true, then expression (5.4a) could be rewritten such this:

$$
\operatorname{Cr}\{\tilde{a}=r\} \geq \pi \equiv \operatorname{Cr}\{\tilde{a} \leq r\} \leq(2-\pi) / 2 \cap \operatorname{Cr}\{\tilde{a} \leq r\} \geq \pi / 2 .
$$

And it is clear that only $\pi=1$ could be applied in expression (5.4b). Respecting (5.3c) and (5.3d) only if $a^{2} \leq r \leq a^{3}$, then $\operatorname{Cr}\{\tilde{a} \geq r\}=\operatorname{Cr}\{\tilde{a} \leq r\}=1 / 2$ is true. According to formulas (5.4), (5.3a), (5.3c) and (5.3d) 
and assuming $\alpha, \beta \geq 0.5$ crisp equivalent of model (5.2) is transformed as follows:

$$
\begin{array}{ll}
\text { Min } & E(\mathrm{Obj})=\left(\frac{\mathbf{c}_{\boldsymbol{1}}+\mathbf{c}_{\boldsymbol{2}}+\mathbf{c}_{\boldsymbol{3}}+\mathbf{c}_{\boldsymbol{4}}}{4}\right) \boldsymbol{x} \\
\text { s.t. } & \\
& \mathbf{A} \boldsymbol{x} \geq(2-2 \alpha) \mathbf{d}_{\mathbf{3}}+(2 \alpha-1) \mathbf{d}_{\boldsymbol{4}} \\
& \mathbf{A}^{\prime} \boldsymbol{x} \leq(2 \beta-1) \mathbf{c}_{\mathbf{1}}+(2-2 \beta) \mathbf{c}_{\mathbf{2}} \\
& \mathbf{B}_{\mathbf{3}} \boldsymbol{x} \geq \boldsymbol{y} \\
& \mathbf{B}_{\mathbf{2}} \boldsymbol{x} \leq \boldsymbol{y} \\
& \boldsymbol{x}, \boldsymbol{y} \geq 0 .
\end{array}
$$

\subsection{Robust credibility-based fuzzy programming}

Robust optimization has been applied several times for handling infeasibility risks in production planning and SC optimization in recent works $[29,31]$. In addition, robust optimization plays an important role in the area of agile SC management systems according to the previous articles. For example, Pan and Nagi [29] resolved uncertainty of demand in AM environment through robust optimization, Hasani et al. [14] applied robust optimization to handle uncertain parameters in agile SC at strategic level. In the proposed planning system, the model in phase I has to minimize variation effects of non-deterministic parameters, but since this phase covers strategic level of planning, it needs robust optimization. According to the theory of robust optimization stated in Ben-Tal et al. [5] book, model should be sensitive to deviations from the optimal value in the OF (optimality robustness) and deviations from constraints feasibility (feasibility robustness) and for this, robustness cost should be mentioned in the OF of the model [21]. In model (5.6), cost of deviation from expected optimality is shown along with coefficient $\delta$ and penalty of deviations from feasibility is shown along with coefficients $\sigma$ and $\lambda$.

$$
\begin{array}{ll}
\text { Min } & E(\mathrm{Obj})+\delta\left(\mathrm{Obj}_{\max }-E(\mathrm{Obj})\right)+\sigma\left(\mathbf{d}_{\mathbf{4}}-(2-2 \alpha) \mathbf{d}_{\mathbf{3}}-(2 \alpha-1) \mathbf{d}_{\mathbf{4}}\right) \\
& \quad+\lambda\left((2 \beta-1) \mathbf{c}_{\mathbf{1}}+(2-2 \beta) \mathbf{c}_{\mathbf{2}}-\mathbf{c}_{\mathbf{1}}\right) \\
\text { s.t. } & \\
& \mathbf{A} \boldsymbol{x} \geq(2-2 \alpha) \mathbf{d}_{\mathbf{3}}+(2 \alpha-1) \mathbf{d}_{\mathbf{4}} \\
& \mathbf{A}^{\prime} \boldsymbol{x} \leq(2 \beta-1) \mathbf{c}_{\mathbf{1}}+(2-2 \beta) \mathbf{c}_{\mathbf{2}} \\
& \mathbf{B}_{\mathbf{3}} \boldsymbol{x} \geq \boldsymbol{y} \\
& \mathbf{B}_{\mathbf{2}} \boldsymbol{x} \leq \boldsymbol{y} \\
& \boldsymbol{x}, \boldsymbol{y} \geq 0, \quad 0.5 \leq \alpha, \beta \leq 1 .
\end{array}
$$

Due to the fact that the OF will not be greater than $\mathrm{Obj}_{\max }$, thus the deviation is considered 0 to difference between expected optimality and the worst optimality. Model (5.6) provides a realistic solution for planning system. In some cases, it is necessary for optimal decision to have a strict planning. As it is observed in the model (5.7), in such cases the most pessimistic values of the possibilistic parameters in the model will be used.

$$
\begin{array}{ll}
\text { Min } & \sup (\mathrm{Obj})=\mathbf{c}_{\boldsymbol{4}} \boldsymbol{x} \\
\text { s.t. } & \mathbf{A} \boldsymbol{x} \geq \sup (\tilde{\mathbf{d}}) \\
& \mathbf{A}^{\prime} \boldsymbol{x} \leq \inf (\tilde{\mathbf{c}}) \\
& \mathbf{B}_{\mathbf{3}} \boldsymbol{x} \geq \boldsymbol{y} \\
& \mathbf{B}_{\mathbf{2}} \boldsymbol{x} \leq \boldsymbol{y} \\
& \boldsymbol{x}, \boldsymbol{y} \geq 0
\end{array}
$$


It is clear that most of the planning issues do not need to spend more money for being cautious as much as HWRCFP approach.

$$
\begin{gathered}
\text { Min } \mathrm{Obj}_{\max }+\sigma\left(\mathbf{d}_{\mathbf{4}}-(2-2 \alpha) \mathbf{d}_{\mathbf{3}}-(2 \alpha-1) \mathbf{d}_{\mathbf{4}}\right)+\lambda\left((2 \beta-1) \mathbf{c}_{\mathbf{1}}+(2-2 \beta) \mathbf{c}_{\mathbf{2}}-\mathbf{c}_{\mathbf{1}}\right) \\
+\phi\left[\left((1-\pi) \mathbf{B}_{\mathbf{4}}+\pi \mathbf{B}_{\mathbf{3}}-\mathbf{B}_{\mathbf{3}}\right) \boldsymbol{x}+\left(\mathbf{B}_{\mathbf{2}}-(1-\pi) \mathbf{B}_{\mathbf{1}}-\pi \mathbf{B}_{\mathbf{2}}\right) \boldsymbol{x}\right]
\end{gathered}
$$

s.t.

$$
\begin{aligned}
& \mathbf{A} \boldsymbol{x} \geq(2-2 \alpha) \mathbf{d}_{\mathbf{3}}+(2 \alpha-1) \mathbf{d}_{\mathbf{4}} \\
& \mathbf{A}^{\prime} \boldsymbol{x} \leq(2 \beta-1) \mathbf{c}_{\mathbf{1}}+(2-2 \beta) \mathbf{c}_{\mathbf{2}} \\
& \mathbf{B}_{\mathbf{3}} \boldsymbol{x} \geq \boldsymbol{y} \\
& \mathbf{B}_{\mathbf{2}} \boldsymbol{x} \leq \boldsymbol{y} \\
& \boldsymbol{x}, \boldsymbol{y} \geq 0, \quad 0.5 \leq \alpha, \beta \leq 1 .
\end{aligned}
$$

\subsection{RCFP for Lean phase of LSC optimization}

In this section, we use the proposed RCFP model to write crisp equivalent MILP model for the uncertain model of lean phase, RCFP formulation is used for both of the Ofs. The second OF has non-deterministic parameter of $\mathrm{Cap}_{j}$, thereupon, optimality robustness is implicated. $\mathrm{Obj}_{\max }$ is calculated using coefficient of $1 / \mathrm{Cap}_{j(1)}$ and according to the theory of fuzzy standard operations (Zadeh 1978) if $\mathrm{Cap}_{j}$ is a positive fuzzy number then $\mathrm{Cap}_{j}^{-1}$ is a positive fuzzy number too with following distribution: $\mathrm{Cap}_{j}^{-1}=\left(\mathrm{Cap}_{j(4)}^{-1}, \operatorname{Cap}_{j(3)}^{-1}, \mathrm{Cap}_{j(2)}^{-1}, \operatorname{Cap}_{j(1)}^{-1}\right)$. Expected value of MRUBF could be calculated regarding to the value of $E\left(\mathrm{Cap}_{j}^{-1}\right)$ in formula (5.9).

$$
\begin{aligned}
& E\left(\frac{1}{\operatorname{Cap}_{j}}\right) \\
& =\frac{\operatorname{Cap}_{j(1)} \operatorname{Cap}_{j(2)} \operatorname{Cap}_{j(3)}+\operatorname{Cap}_{j(1)} \operatorname{Cap}_{j(3)} \operatorname{Cap}_{j(4)}+\operatorname{Cap}_{j(1)} \operatorname{Cap}_{j(2)} \operatorname{Cap}_{j(4)}+\operatorname{Cap}_{j(2)} \operatorname{Cap}_{j(3)} \operatorname{Cap}_{j(4)}}{4 \times \operatorname{Cap}_{j(4)} \operatorname{Cap}_{j(3)} \operatorname{Cap}_{j(2)} \operatorname{Cap}_{j(1)}} .
\end{aligned}
$$

Both the main OF and robustness penalties should have the same unit to be collected, otherwise they need to be normalized, so on any of the robustness penalty words in the second OF (i.e. $R_{2}$ ) should be multiplied by $E\left(|T|^{-1}|J|^{-1} \mathrm{Cap}_{j}^{-1}\right)$ to have the same unit with $R_{2}$. In the following model, in the first OF, unit of $R_{1}$ and $\mathrm{TC}^{1 \text { nd }}$ is the cost unit (i.e. US $\$$ ). After thus unit of $\sigma, \eta, \psi$ and $\tau$, will be item $/ \$$. Since MRUBF is MAE of production volume then MRUBF, $R_{2}$ and corresponding robustness coefficients have no unit. Robustness coefficients of the $R_{2}$ means: Increasing the value of MRUBF when penalty terms associated with each robustness coefficient increase as much as one unit.

$$
\begin{aligned}
\operatorname{Min} R_{1}= & \mathrm{TC}^{1 \mathrm{nd}}+\sigma \sum_{t}\left[\operatorname{need}_{t(4)}^{C}-\left(2-2 \alpha_{t}^{C}\right) \operatorname{need}_{t(3)}^{C}-\left(2 \alpha_{t}^{C}-1\right) \operatorname{need}_{t(4)}^{C}\right] \\
& +\eta \sum_{f} \sum_{t}\left[\operatorname{dem}_{f t(4)}^{F}-\left(2-2 \alpha_{f t}^{F}\right) \operatorname{dem}_{f t(3)}^{F}-\left(2 \alpha_{f t}^{F}-1\right) \operatorname{dem}_{f t(4)}^{F}\right] \\
& +\psi \sum_{j}\left(\left(2 \beta_{j}-1\right) \operatorname{Cap}_{j(1)}+\left(2-2 \beta_{j}\right) \operatorname{Cap}_{j(2)}-\operatorname{Cap}_{j(1)}\right) \\
& +\tau \sum_{j} \sum_{r} \sum_{t}\left[\operatorname{Ss}_{j r t(4)}^{C}-\left(2-2 \alpha_{j r t}^{\mathrm{Ss}}\right) \operatorname{Ss}_{j r t(3)}^{C}-\left(2 \alpha_{j r t}^{\mathrm{Ss}}-1\right) \mathrm{Ss}_{j r t(4)}^{C}\right] \\
\operatorname{Min} R_{2}= & E(\mathrm{MRUBF})+\delta\left[\frac{\sum_{j} \frac{1}{\operatorname{Cap}_{j(1)}} \sum_{t}\left|\left(\sum_{f} Y_{j f t}^{F}+Y_{j t}^{C}\right)-\left(\frac{\sum_{f} \sum_{t} Y_{j f t}^{F}+\sum_{t} Y_{j t}^{C}}{|T|}\right)\right|}{|T||J|}-E(\mathrm{MRUBF})\right]
\end{aligned}
$$




$$
\begin{aligned}
& +\sum_{j} E\left(\frac{1}{|T||J| \mathrm{Cap}_{j}}\right) \sigma^{\prime} \sum_{t}\left[\operatorname{need}_{t(4)}^{C}-\left(2-2 \alpha_{t}^{C}\right) \operatorname{need}_{t(3)}^{C}-\left(2 \alpha_{t}^{C}-1\right) \operatorname{need}_{t(4)}^{C}\right] \\
& +\sum_{j} E\left(\frac{1}{|T||J| \mathrm{Cap}_{j}}\right) \eta^{\prime} \sum_{f} \sum_{t}\left[\operatorname{dem}_{f t(4)}^{F}-\left(2-2 \alpha_{f t}^{F}\right) \operatorname{dem}_{f t(3)}^{F}-\left(2 \alpha_{f t}^{F}-1\right) \operatorname{dem}_{f t(4)}^{F}\right] \\
& +\sum_{j} E\left(\frac{1}{|T||J| \mathrm{Cap}_{j}}\right) \psi^{\prime} \sum_{j}\left(\left(2 \beta_{j}-1\right) \operatorname{Cap}_{j(1)}+\left(2-2 \beta_{j}\right) \operatorname{Cap}_{j(2)}-\mathrm{Cap}_{j(1)}\right) \\
& +\sum_{j} E\left(\frac{1}{|T||J| \mathrm{Cap}_{j}}\right) \tau^{\prime} \sum_{j} \sum_{r} \frac{1}{\gamma_{r}^{C}} \sum_{t}\left[\operatorname{Ss}_{j r t(4)}^{C}-\left(2-2 \alpha_{j r t}^{\mathrm{Ss}}\right) \mathrm{Ss}_{j r t(3)}^{C}-\left(2 \alpha_{j r t}^{\mathrm{Ss}}-1\right) \mathrm{Ss}_{j r t(4)}^{C}\right] \\
E(\mathrm{MRUBF})= & \sum_{j} \sum_{t}\left\{E\left(\frac{1}{\mathrm{Cap}_{j}}\right) \times \frac{\left|\left(\sum_{f} Y_{j f t}^{F}+Y_{j t}^{C}\right)-\left(\frac{\sum_{f} \sum_{t} Y_{j f t}^{F}+\sum_{t} Y_{j t}^{C}}{|T|}\right)\right|}{|T||J|}\right\}
\end{aligned}
$$

Subject to

$$
\begin{array}{rlrl}
\sum_{j} \mathrm{OS}_{j t}^{C}+\sum_{j} Y_{j t}^{C} & \geq\left(2-2 \alpha_{t}^{C}\right) \operatorname{need}_{t(3)}^{C}+\left(2 \alpha_{t}^{C}-1\right) \operatorname{need}_{t(4)}^{C} & & \forall t \\
\sum_{j} \mathrm{OS}_{j f t}^{F}+\sum_{j} Y_{j f t}^{F} & \geq\left(2-2 \alpha_{f t}^{F}\right) \operatorname{dem}_{f t(3)}^{F}+\left(2 \alpha_{f t}^{F}-1\right) \operatorname{dem}_{f t(4)}^{F} & & \forall f, t \\
\sum_{i}\left(1-\mathrm{DR}_{i r(2)}^{C}\right) X_{i j r t}^{C} & \geq I_{j r t}^{C}+\gamma_{r}^{C} Y_{j t}^{C}+\gamma_{r}^{F} \sum_{f} Y_{j f t}^{F}-I_{j r, t-1}^{C} & & \forall j, r, t \\
\sum_{i}\left(1-\mathrm{DR}_{i r(3)}^{C}\right) X_{i j r t}^{C} & \leq I_{j r t}^{C}+\gamma_{r}^{C} Y_{j t}^{C}+\gamma_{r}^{F} \sum_{f} Y_{j f t}^{F}-I_{j r, t-1}^{C} & & \forall j, r, t \\
O_{i r t} \mathrm{SC}_{i r}^{C-M i n} & \leq \sum_{j} X_{i j r t}^{C} \leq O_{i r t} \mathrm{SC}_{i r}^{C-M a x} & \forall i, r, t \\
\sum_{r} \sum_{i} u v_{r}^{C}\left(X_{i j r t}^{C}+I_{j r, t-1}^{C}\right) & \leq \mathrm{WS}_{j}^{\mathrm{L}} & \forall j, t \\
Y_{j t}^{C}+\sum_{f} Y_{j f t}^{F} & \leq\left(2 \beta_{j}-1\right) \mathrm{Cap}_{j(1)}+\left(2-2 \beta_{j}\right) \mathrm{Cap}_{j(2)} & \forall j, t \\
I_{j r t}^{C} & \geq\left(2-2 \alpha_{j r t}^{\mathrm{Ss}}\right) \operatorname{Ss}_{j r t(3)}^{C}+\left(2 \alpha_{j r t}^{\mathrm{Ss}}-1\right) \mathrm{Ss}_{j r t(4)}^{C} & \forall j, r, t \\
\mathrm{OS}_{j t}^{C}+Y_{j t}^{C} & =Q_{j t}^{C} & \forall j, t \\
\operatorname{OS}_{j f t}^{F}+Y_{j f t}^{F} & =Q_{j f t}^{F} & \forall j, f, t .
\end{array}
$$

\section{SOLUtion PROCEDURE}

Given that, in this model, the optimal minimum confidence levels are obtained, it is not considered to be an interactive model. Given the confidence levels (e.g. $\left.\alpha_{t}^{C}, \alpha_{f t}^{F}, \beta_{j}, \alpha_{j r t}^{\mathrm{Ss}}\right)$, to analyze and find the best solution, problem needs to be solved many times so we consider them as variables and their optimal values through the final solution is achieved. In the solution method, each of Ofs is individually optimized to attain positive idealistic solutions, i.e. $R_{1}^{\mathrm{PIS}}$ and $R_{2}^{\mathrm{PIS}}$, also negative idealistic solutions $R_{1}^{\mathrm{NIS}}$ and $R_{2}^{\mathrm{NIS}}$ [37] to achieve fuzzy membership functions of the Ofs that represent satisfaction degree of the associate Ofs, $R_{2}^{\text {NIS }}$ is obtained with applying optimal solution set (obtained from individually solving the first OF), in the single-objective model that is to optimize $R_{2}$. Then the linear membership function $\left(\mu_{i}\right)$ for satisfaction degree of the $\mathrm{OF}_{i}$ will be 


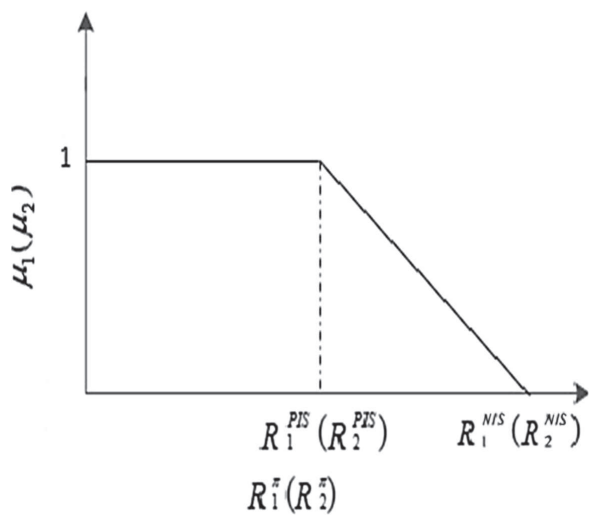

FiguRE 4. Linear membership function for $R_{1}\left(R_{2}\right)$.

acquired.

$$
\begin{aligned}
& \mu_{1}= \begin{cases}1 & \text { if } R_{1} \leq R_{1}^{\mathrm{PIS}} \\
\frac{R_{1}^{\mathrm{NIS}}-R_{1}}{R_{1}^{\mathrm{IIS}}-R_{1}^{\mathrm{PIS}}} & \text { if } R_{1}^{\mathrm{PIS}} \leq R_{1} \leq R_{1}^{\mathrm{PIS}} \\
0 & \text { if } R_{1} \geq R_{1}^{\mathrm{NIS}}\end{cases} \\
& \mu_{2}= \begin{cases}1 & \text { if } R_{2} \leq R_{2}^{\mathrm{PIS}} \\
\frac{R_{2}^{\mathrm{NIS}}-R_{2}}{R_{2}^{\mathrm{NIS}}-R_{2}^{\mathrm{PIS}}} & \text { if } R_{2}^{\mathrm{PIS}} \leq R_{2} \leq R_{2}^{\mathrm{NIS}} \\
0 & \text { if } R_{2} \geq R_{2}^{\mathrm{NIS}} .\end{cases}
\end{aligned}
$$

To continue the multi-objective programming method, the bi-objective optimization is converted to the singleobjective optimization using the obtained membership functions and $\mathrm{TH}$ aggregation function [37] as follows (Fig. 4):

$$
\begin{array}{ll}
\max \mu & =\rho \mu_{0}+(1-\rho)\left(\theta_{1} \mu_{1}+\theta_{2} \mu_{2}\right) \\
\text { s.t. } & \mu_{0} \leq \mu_{1}, \\
\mu_{0} & \leq \mu_{2}, \\
\mu_{1} & =\frac{R_{1}^{\mathrm{NIS}}-R_{1}}{R_{1}^{\mathrm{NIS}}-R_{1}^{\pi-P I S}}, \\
\mu_{2} & =\frac{R_{2}^{\mathrm{NIS}}-R_{2}}{R_{2}^{\mathrm{NIS}}-R_{2}^{\mathrm{PIS}},} \\
\mu_{0} & \geq 0, \quad x \in F(x) .
\end{array}
$$

In the attained single-objective model, $\mu_{0}$ signifies the minimum satisfaction degree of Ofs, TH coefficients, i.e. $\rho$ and $\theta_{i}$ are the importance coefficients of the minimum satisfaction degree of objectives and the satisfaction degree of $\mathrm{OF}_{i}$ respectively. $F(x)$ signifies crisp equivalent of constraint sets of the corresponding model and $\boldsymbol{X}$ is vector of variable set in the given model. By setting various values for $\rho$ and $\theta_{i}$ (randomly or with regard to decision maker diagnosis and directions) different solutions, Pareto optimal solutions, is obtainable which eventually the best set of solutions is chosen from the perspective of the decision maker. Figure 5 shows the described process step by step to solve the whole problem. The robustness parameters such as $\sigma, \eta, \psi, \tau$ and $\delta$ are usually meaningful and initialization of them are generally consistent with expert opinion or the results of related calculations. So, such approach generally is not appropriate to change optimum solution. For example, $\sigma$ and $\eta$ parameters could be regarded as penalties not to satisfy customer demands which are familiar for the sales 


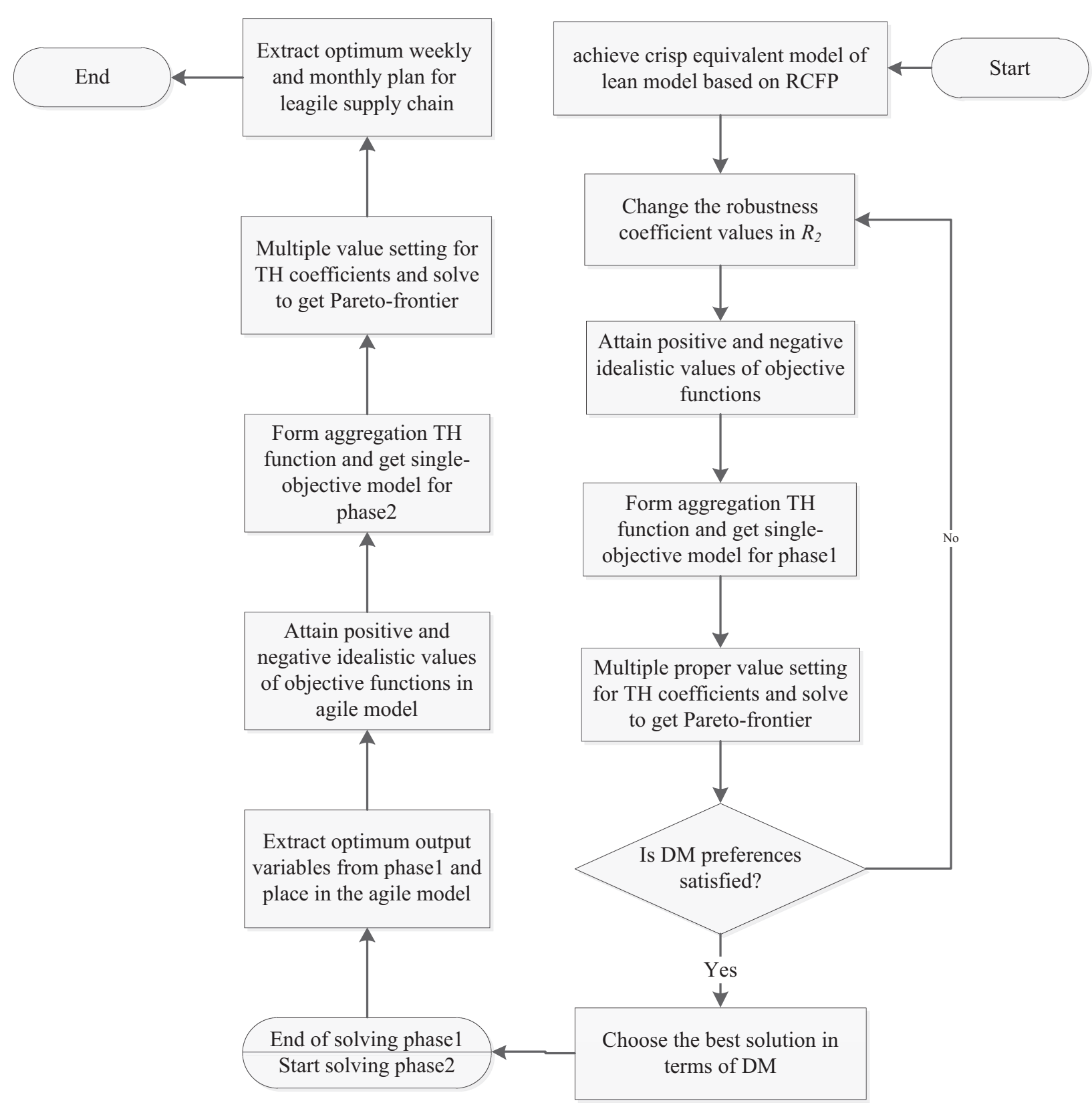

FIGURE 5. Schematic solving process of LSC problem.

management, marketing and CRM departments. And $\tau$ parameter could be calculated as the probability of inventory shortage multiplied by unit cost of lost-sales. $\psi$ means the imposed cost on company for increasing a unit of capacity. However, if a small change in a robustness parameter is negligible in terms of management, it could also be considered as an interactive parameter.

After obtaining the preferred optimal solutions of first phase of problem, $Q_{t}^{C}$ and $Q_{f t}^{F}$ as inputs of the second phase of problem are extracted and solving would be started. To solve it, TH multi-objective programming 
TABLE 1. Estimated required common boards and demand of low power analog transmitter in moths.

\begin{tabular}{lll}
\hline \hline Period (month) & Predicted need of common board & Predicted demand of 10 Watt Transmitter \\
\hline 1 & $(0,0,0,0)$ & $(0,0,0,0)$ \\
2 & $(0,0,0,0)$ & $(0,0,0,0)$ \\
3 & $(0,0,0,0)$ & $(0,0,0,0)$ \\
4 & $(0,0,0,0)$ & $(0,0,0,0)$ \\
5 & $(0,0,0,0)$ & $(0,0,0,0)$ \\
6 & $(112,130,135,140)$ & $(224,228,230,235)$ \\
7 & $(0,0,0,0)$ & $(0,0,0,0)$ \\
8 & $(0,0,0,0)$ & $(0,0,0,0)$ \\
9 & $(0,0,0,0)$ & $(0,0,0,0)$ \\
10 & $(0,0,0,0)$ & $(0,0,0,0)$ \\
11 & $(0,0,0,0)$ & $(0,0,0,0)$ \\
12 & $(110,120,124,132)$ & $(220,230,240,245)$ \\
\hline
\end{tabular}

TABle 2. Cost and capacity data at phase I.

\begin{tabular}{lll}
\hline \hline Costs & $\begin{array}{l}\text { Common } \\
\text { board }\end{array}$ & $\begin{array}{l}10 \\
\text { Transmitter }\end{array}$ \\
\hline $\begin{array}{l}\text { Production cost }(\$ / \text { unit }) \\
\begin{array}{l}\text { Transportation cost to assembly } \\
\text { plant }(\$ / \text { unit) }\end{array}\end{array}$ & 61.8 & 30.25 \\
\hline Outsourcing cost $(\$ /$ unit $)$ & 600 & 3 \\
\hline $\begin{array}{l}\text { Capacity of production shop } \\
\left(\mathrm{Cap}_{j(1)}, \mathrm{Cap}_{j(2)}, \mathrm{Cap}_{j(3)}, \mathrm{Cap}_{j(4)}\right)\end{array}$ & $(135,140,150,154)$ \\
\hline
\end{tabular}

method is used similar to that used in the first phase, and the satisfaction degree of $\mathrm{TC}^{2 \text { nd }}$ and CSL Ofs (i.e. $\mu_{1}^{\prime}$ and $\mu_{2}^{\prime}$, respectively) would be defined.

\section{Case study implementation}

In this section, to evaluate and demonstrate applicability of proposed structure, data extracted from a real industrial case study which is appropriate to the suggested LSC optimization issue, is placed in the model. This company is one of the main manufacturers of analog and digital equipment and radio transmitters and has an active assembly facility that purchase some new certain components such as demodulator tuner of DVBT2/DVBS2/DVBC. The specific-ordered products manufactured at this facility include high power 100 and 200-Watt transmitters and Remux DVBT2/DVBS2 receivers and PVR (Personal video recorder) whose main distribution boards is assembled in production center. The tender object was production and delivery of radio and television transmitters and receivers to three provinces. In Table 1, the required amount of semimanufactured products (common boards) that is a merger of the main sub-racks and boards and the low power analog transmitter demands are presented.

Units of costs is considered in dollar, Unit costs of production, transportation and outsourcing are shown in Table 2. Given that production capacity is calculated all along of the one-year planning horizon, and in the other hand there is the possibility of increasing capacity eventually the experts identify four prominent point of corresponding trapezoidal fuzzy number. 


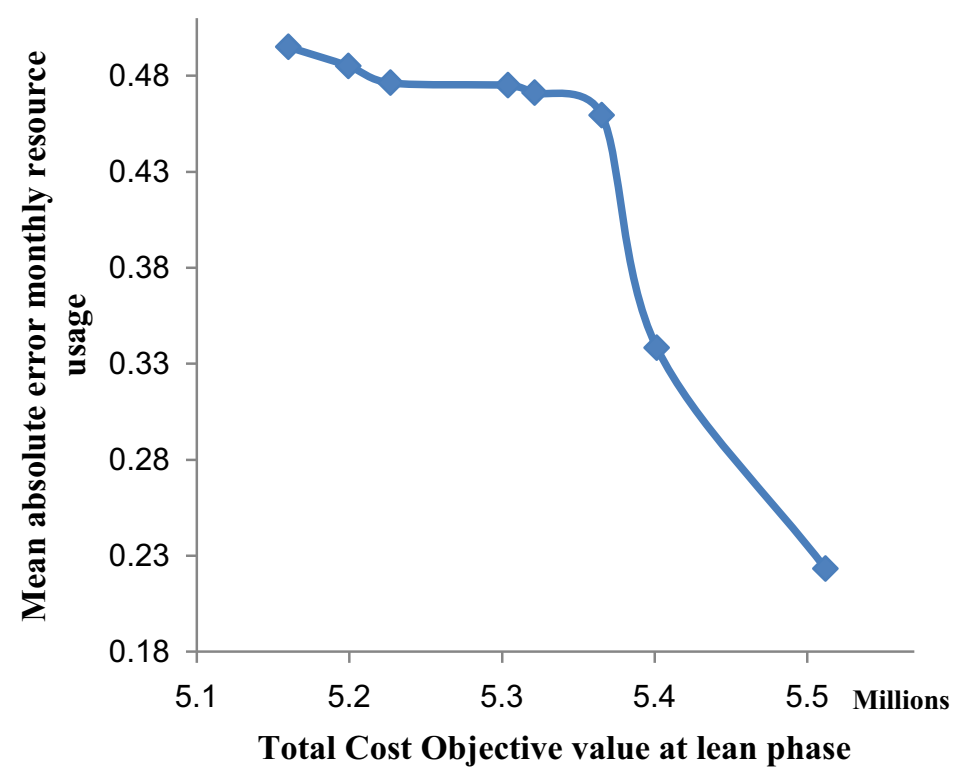

FiguRE 6. Optimum means absolute error of monthly resource usage vs. optimum total cost at lean phase. When $\delta=0.1, \sigma^{\prime}=0.001, \eta^{\prime}=0.001, \psi^{\prime}=5 \times 10^{-4}, \tau^{\prime}=2 \times 10^{-4}$.

Due to the fact that the production of a low-power transmitter requires the same capacity the capacity parameters for the production of common boards has not been separated. The extracted data is used to justify and validate the leagile optimization model, both models (for first and second phase) and the presented solution method are coded by GAMS 23.5 optimization software and CPLEX solver from IBM is used to solve on a Core 2 Due processor PC with $2.53 \mathrm{GHz}$ CPU and $4 \mathrm{~GB}$ of Ram. The average CPU time which is spent for each run was $10 \mathrm{~s}$. In solving the first phase of problem, as can be seen in Table 3 and Figures 6 and 7, the values of the Ofs and comparison charts the Ofs of total LM cost and balance factor in the consumption of resources and the degree of membership to them, respectively, shows that the two Ofs are in conflict with each other. In all numerical tests were carried out, the fixed robustness coefficient values have been set as follows, $\sigma=200 \$$, $\eta=250 \$, \psi=40 \$$, and $\tau=20 \$$, which are recommended by the experts based on knowledge and experience.

Regarding to the TH aggregation function, if the value of $\rho$ is lower, for example $\rho=0.2$, solutions that have a bigger difference in the coefficients $\theta_{i}\left(\right.$ e.g. $\left|\theta_{2}-\theta_{1}\right|=\Delta \theta \geq 0.4$ ), would be more appropriate, also if the value of $\rho$ is high (e.g. $\rho \geq 0.5)$, the difference in the coefficients $\theta_{i}$ should not be high (e.g. $\left.\Delta \theta \leq 0.2\right)$, in this case, the solutions would be more qualified to be elected. As the results show, with reducing value of $\sigma^{\prime}$ and $\eta^{\prime}, R_{2} \mathrm{OF}$ are naturally improves, but this reduction also improves $R_{2}$ OF; Reduction of these coefficients results decreasing the average optimum confidence levels of and, as well decreasing the optimum confidence levels improves $R_{1}$ OF value, so that could explain the decrease in $R_{1}$ (Fig. 8).

In Table 4, solutions associated with three uncertainty programming approach, i.e. RFCP, HWRFCP and SWRFCP is displayed. As evidenced by the results, programming by HWRFCP approach presents the worse $\mathrm{OF}$ values.

The value of MRUBF OF with the same parameters never be lower than the values obtained in the HWRCFP model. According to the results, the value of parameters and their relationship with each other and preferences of the company's management team, the preferred solution of problem at the first phase, is chosen and output quantities of produced and outsourced items shown in Table 5, is extracted through first phase to be entered in second phase. 


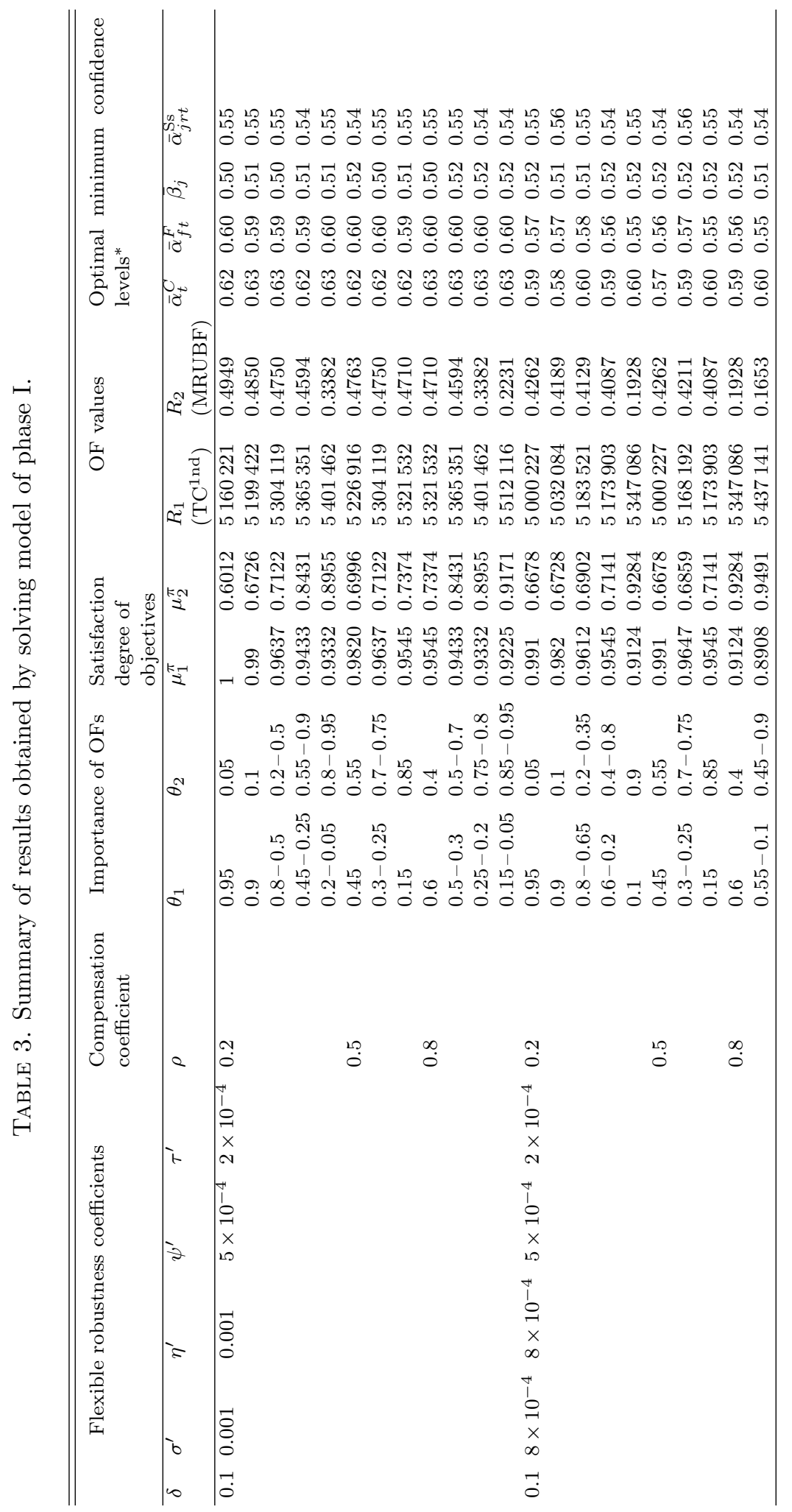




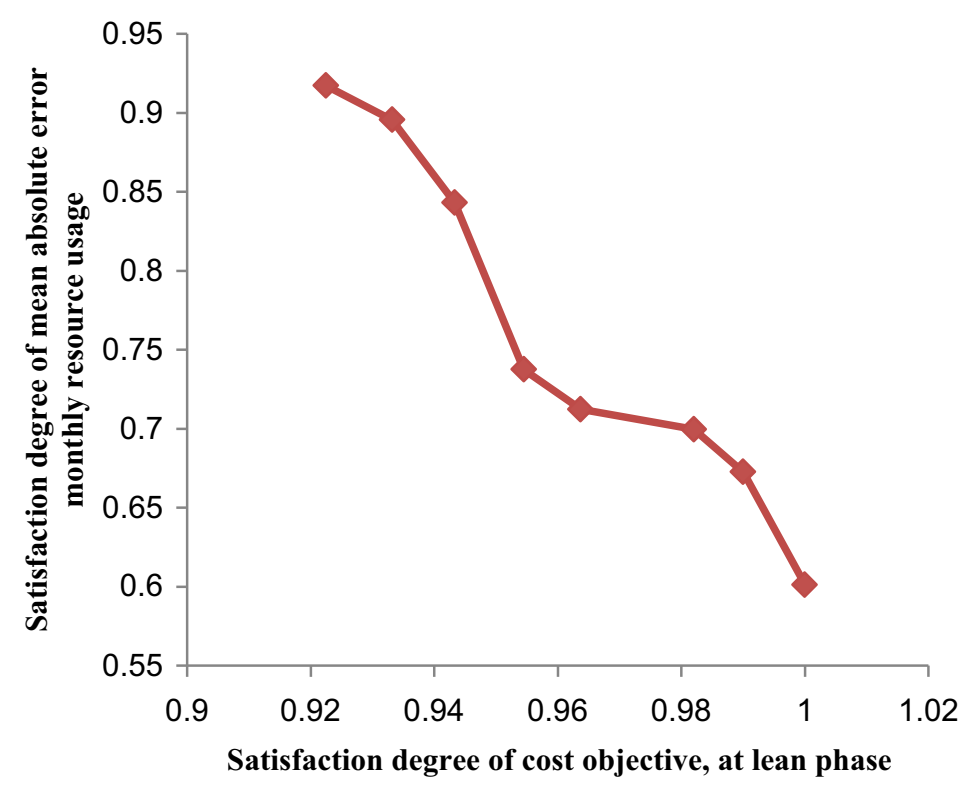

FiguRE 7. Satisfaction degree of OFs at phase I (Lean plan).

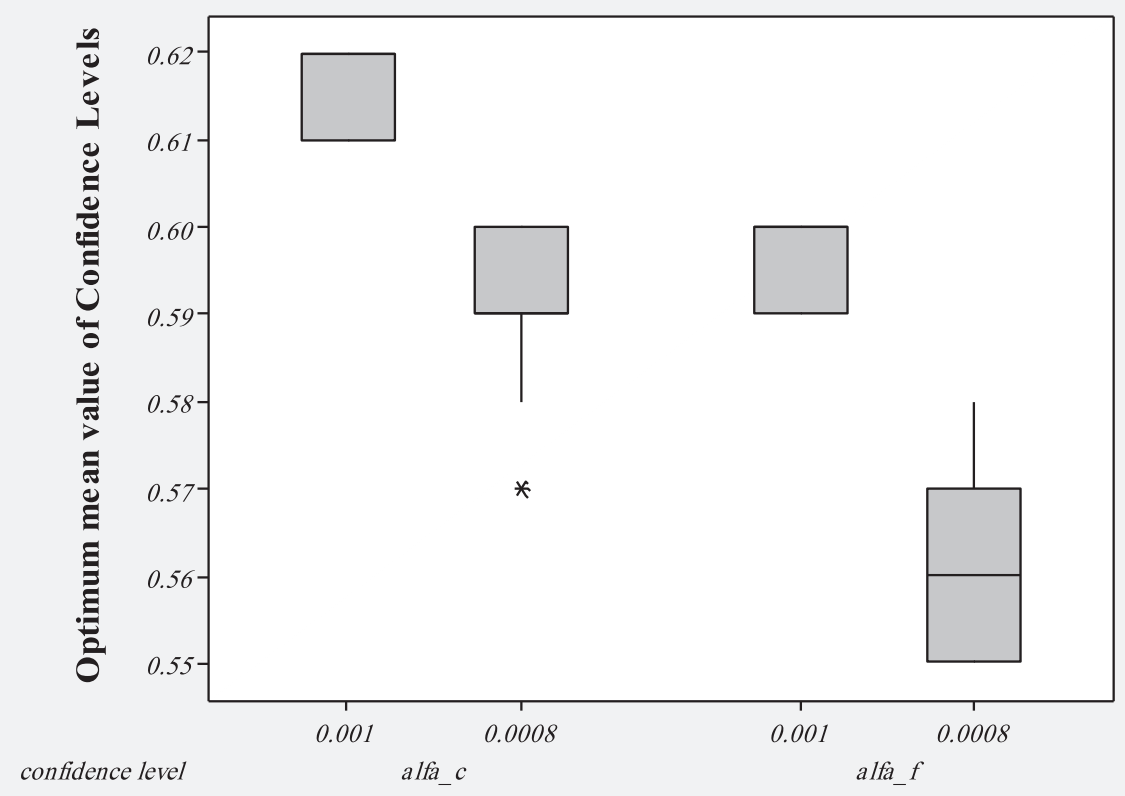

Robbustness Parameters of s' and $\eta$

FiguRE 8. Correlation between the robustness coefficients $\left(\sigma^{\prime}, \eta^{\prime}\right)$ and the average optimum confidence levels associated with the constraints. 
TABLE 4. Results of solving RCFP, HWRCFP and SWRCFP models.

\begin{tabular}{llllll}
\hline \hline \multicolumn{2}{c}{ RCFP } & \multicolumn{2}{c}{ HWRCFP } & \multicolumn{2}{c}{ SWRCFP } \\
\hline$R_{1}$ & $R_{2}$ & $R_{1}$ & $R_{2}$ & $R_{1}$ & $R_{2}$ \\
\hline 5160221 & 0.4949 & 5136509 & 0.52270 & 5160221 & 0.5098 \\
5304119 & 0.475 & 5278158 & 0.50965 & 5304119 & 0.4742 \\
5401462 & 0.3382 & 5406251 & 0.34972 & 5401462 & 0.3396 \\
5321532 & 0.471 & 5303182 & 0.50822 & 5321532 & 0.4750 \\
5365351 & 0.4594 & 5341307 & 0.48004 & 5365351 & 0.4652 \\
5512116 & 0.2231 & 5486589 & 0.23429 & 5512116 & 0.2264 \\
5208134 & 0.437 & 5200544 & 0.46121 & 5208134 & 0.4253 \\
\hline
\end{tabular}

TABLE 5. Preferred solution of lean phase, inputs agile phase.

\begin{tabular}{|c|c|c|c|c|c|c|c|c|c|c|c|c|}
\hline \multirow{3}{*}{$\begin{array}{l}\text { Preferred solution } \\
\text { Item }\end{array}$} & \multicolumn{12}{|c|}{$\begin{array}{l}\rho^{*}=0.5 \Theta_{1}^{*}=0.45, \quad \Theta_{2}^{*}=0.55 \quad \mu_{1}=0.981 \\
\mu_{2}=0.6996 \quad R_{2}^{*}=0.6571, \quad R_{1}^{*}=5198697\end{array}$} \\
\hline & \multicolumn{12}{|c|}{ Periods (month) } \\
\hline & 1 & 2 & 3 & 4 & 5 & 6 & 7 & 8 & 9 & 10 & 11 & 12 \\
\hline $\begin{array}{l}\text { Deliverable Common boards } \\
\left(Q_{j t}^{C}\right)\end{array}$ & 0 & 0 & 27 & 52 & 54 & 0 & 0 & 0 & 24 & 49 & 50 & 0 \\
\hline $\begin{array}{l}\text { Deliverable } 10 \text { Watt trans- } \\
\text { mitter }\left(Q_{j f t}^{F}\right)\end{array}$ & 0 & 0 & 47 & 90 & 92 & 0 & 0 & 0 & 46 & 95 & 97 & 0 \\
\hline
\end{tabular}

Since inputs for model of second phase should be entered at the beginning of the month and the final assembly should be started one month before the outbreak of the demands, thereupon in the first phase, the demands should be responded by until one month ago (see Tab. 5), The results are shown in Table 6.

As the results in Table 6 and graphs in Figures 9 and 10 shows, by improving customer service level, the total cost of the second phase rises with high intensity and can be concluded that customer responsiveness price is too high in the company environment.

\section{Conclusion}

To include both lean and agile principles in a progressive industry system, a pseudo-hierarchical planning structure is proposed in this paper. The presented leagile supply chain optimization model is comprised of two phases. The mid-term one tends to plan mass production of common finished and semi-finished products, so that is why it orients lean manufacturing whereas the shot-term one inclines to schedule order-driven production. Thus, it is more compatible with agile manufacturing, also the new mathematical modeling contributions is presented to cope with main agility principles. The proposed model, uses a utility function to set balance between different parameters of the model including price, quality and customer satisfaction. In addition, a new multi objective function is designed to enhance the responsibility of the system. Because of the need to predict and estimate some parameters in phase I, the proposed structure applies a robust credibility-based fuzzy programming to deal with unavoidable uncertainty as infeasibility is so costly. The prosed model and solution procedure is applied to a real industrial case study to demonstrate applicability of the conducted study. In this respect, the results of first phase are converted to the second phase and according to the results by improving customer service level, the total cost of the second phase rises with high intensity which means customer responsiveness price is too high in the company environment. For the future works, the earliness and tardiness prevention could be brought into account in lean phase. Also, considering agile allocations and proper alliances 
TABLE 6. Summary of results by solving model of agile phase.

\begin{tabular}{|c|c|c|c|c|c|c|}
\hline \multirow{2}{*}{$\begin{array}{l}\text { Compensation } \\
\text { coefficient } \\
\rho^{\prime} \\
\end{array}$} & \multirow{2}{*}{$\begin{array}{l}\text { Importance of OFs } \\
\Theta_{1}^{\prime}=1-\Theta_{2}^{\prime}\end{array}$} & \multicolumn{2}{|c|}{$\begin{array}{l}\text { Satisfaction } \\
\text { objectives }\end{array}$} & egree of & \multicolumn{2}{|c|}{ OF values } \\
\hline & & $\mu_{0}^{\prime *}$ & $\mu_{1}^{\prime}$ & $\mu_{2}^{\prime}$ & $\mathrm{TC}^{2 \mathrm{nd}}$ & CSL \\
\hline \multirow[t]{5}{*}{0.1} & $0.75-0.9$ & 0.002 & 1 & 0.002 & 1174992 & 0.820 \\
\hline & 0.7 & 0.269 & 0.853 & 0.269 & 5344430 & 0.865 \\
\hline & $0.5-0.65$ & 0.498 & 0.694 & 0.498 & 8822392 & 0.903 \\
\hline & 0.45 & 0.582 & 0.582 & 0.582 & 10832598 & 0.917 \\
\hline & $0.1-0.4$ & 0.001 & 0.001 & 0.998 & 17916138 & 0.987 \\
\hline \multirow[t]{6}{*}{0.15} & $0.8-0.9$ & 0.002 & 1 & 0.002 & 1174992 & 0.820 \\
\hline & 0.75 & 0.229 & 0.878 & 0.229 & 4000021 & 0.858 \\
\hline & $0.55-0.7$ & 0.498 & 0.694 & 0.498 & 8822392 & 0.903 \\
\hline & $0.45-0.5$ & 0.582 & 0.582 & 0.582 & 10832598 & 0.917 \\
\hline & 0.4 & 0.350 & 0.350 & 0.754 & 16335383 & 0.946 \\
\hline & $0.1-0.35$ & 0.001 & 0.001 & 0.998 & 17916138 & 0.987 \\
\hline \multirow[t]{7}{*}{0.2} & $0.85-0.9$ & 0.002 & 1 & 0.002 & 1174992 & 0.820 \\
\hline & 0.8 & 0.229 & 0.878 & 0.229 & 4000021 & 0.858 \\
\hline & 0.75 & 0.269 & 0.853 & 0.269 & 5344430 & 0.865 \\
\hline & $0.6-0.7$ & 0.498 & 0.694 & 0.498 & 8822392 & 0.903 \\
\hline & $0.55-0.4$ & 0.582 & 0.582 & 0.582 & 10832598 & 0.917 \\
\hline & 0.35 & 0.011 & 0.011 & 0.991 & 17728672 & 0.986 \\
\hline & $0.1-0.3$ & 0.001 & 0.001 & 0.998 & 17916138 & 0.987 \\
\hline \multirow[t]{5}{*}{0.35} & 0.9 & 0.269 & 0.853 & 0.269 & 5344430 & 0.865 \\
\hline & $0.7-0.85$ & 0.498 & 0.694 & 0.498 & 8822392 & 0.903 \\
\hline & $0.25-0.65$ & 0.582 & 0.582 & 0.582 & 10832598 & 0.917 \\
\hline & 0.2 & 0.011 & 0.011 & 0.991 & 17728672 & 0.986 \\
\hline & $0.1-0.15$ & 0.001 & 0.001 & 0.998 & 17916138 & 0.987 \\
\hline \multirow[t]{4}{*}{0.4} & $0.75-0.9$ & 0.498 & 0.694 & 0.498 & 8822392 & 0.903 \\
\hline & $0.2-0.7$ & 0.582 & 0.582 & 0.582 & 10832598 & 0.917 \\
\hline & 0.15 & 0.350 & 0.350 & 0.754 & 16335383 & 0.946 \\
\hline & 0.1 & 0.001 & 0.001 & 0.998 & 17916138 & 0.987 \\
\hline \multirow[t]{2}{*}{0.45} & $0.8-0.9$ & 0.498 & 0.694 & 0.498 & 8822392 & 0.903 \\
\hline & $0.1-0.75$ & 0.582 & 0.582 & 0.582 & 10832598 & 0.917 \\
\hline \multirow[t]{2}{*}{0.5} & $0.85-0.9$ & 0.498 & 0.694 & 0.498 & 8822392 & 0.903 \\
\hline & $0.1-0.8$ & 0.582 & 0.582 & 0.582 & 10832598 & 0.917 \\
\hline $0.55-0.9$ & $0.1-0.9$ & 0.582 & 0.582 & 0.582 & 10832598 & 0.917 \\
\hline
\end{tabular}

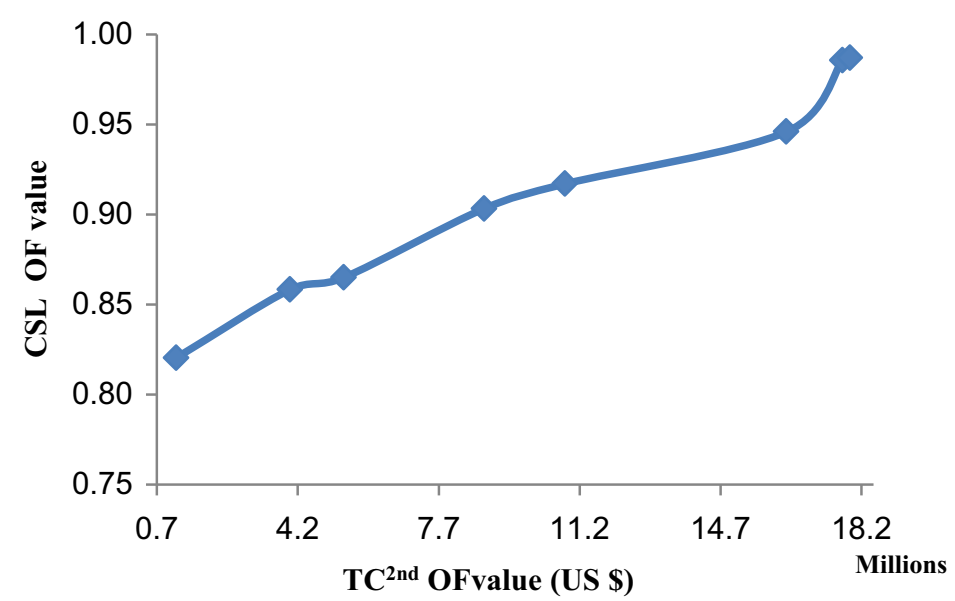

Figure 9. Optimum customer service value vs. optimum total cost at agile phase. 


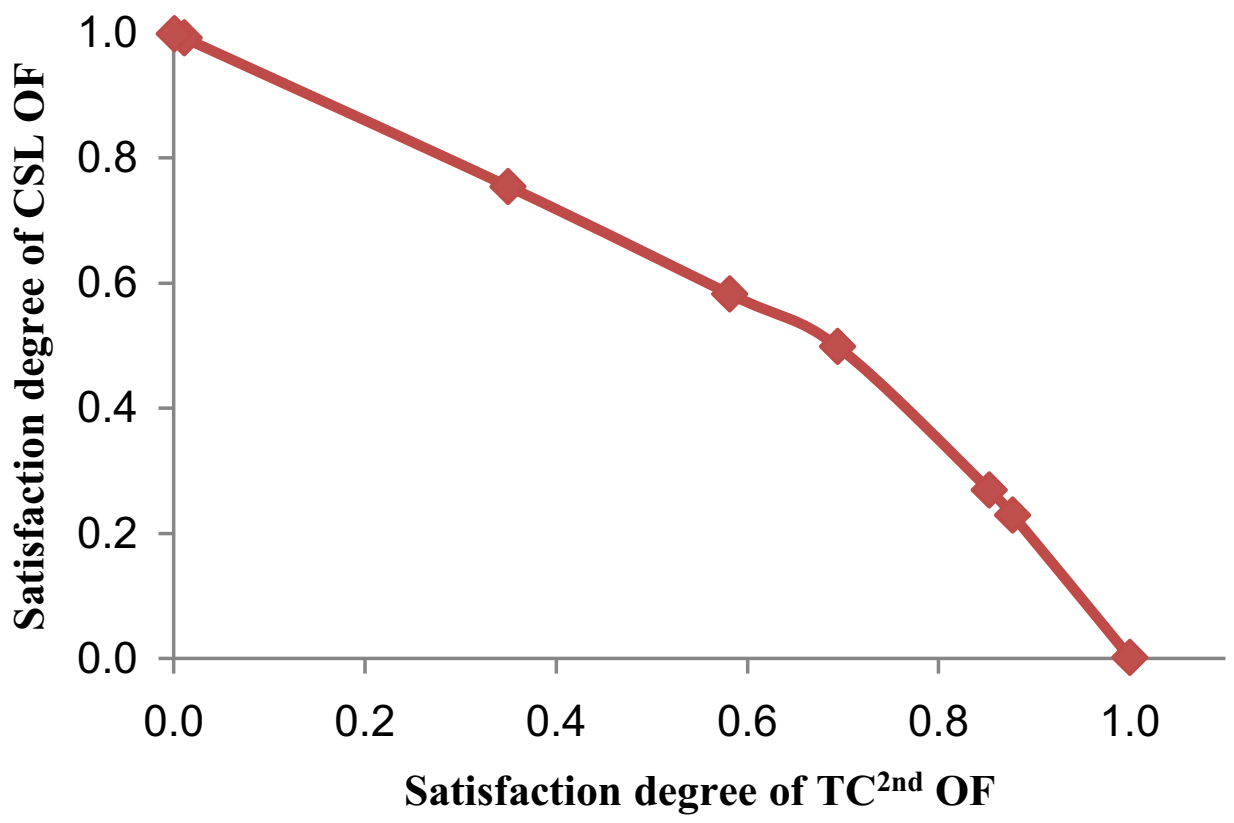

Figure 10. Satisfaction degree of OFs at phase II (Agile plan).

among industrial centers to get over disruptions could be another research direction and in such a way to overcome longer time of solving MILP an efficient exact solution method like benders decomposition could be useful.

\section{Appendix A. Nomenclature}

\begin{tabular}{ll}
\hline \multicolumn{2}{l}{ Indices } \\
$i$ & Index of suppliers $(i=1,2, \ldots, I)$ \\
$j$ & Index of main production centers $(j=1,2, \ldots, J)$ \\
$r$ & Index of common parts (as raw material) types $(r=1,2, \ldots, R)$ \\
$f$ & Index of functional product types $(f=1,2, \ldots, F)$ \\
$t$ & Index of time periods in phase $\mathrm{I}(t=1,2, \ldots, T)$ \\
$M$ & Index of fixed locations of customers $(m=1,2, \ldots, M)$ \\
$G$ & Index of innovative product types $(g=1,2, \ldots, G)$ \\
$i^{\prime}$ & Index of customized element suppliers $\left(i^{\prime}=1,2, \ldots, I^{\prime}\right)$ \\
$S$ & Index of time periods in phase II which certain elements are purchased and stored on \\
& $\left(s=1,2, \ldots, T^{\prime}\right)$ \\
$t^{\prime}$ & Index of time periods in phase II which inventory are consumed on $\left(t^{\prime}=1,2, \ldots, T^{\prime}\right)$ \\
&
\end{tabular}




\begin{tabular}{|c|c|c|c|}
\hline $\mathrm{cp}_{j f}^{F}$ & $\begin{array}{l}\text { Unit production cost to produce functional } \\
\text { product } f \text { in production center } j\end{array}$ & $\mathrm{DR}_{i r}^{C}$ & Defective rate of part $r$ at period $t$ \\
\hline $\mathrm{cp}_{j}^{C}$ & $\begin{array}{l}\text { Unit production and assembly cost of com- } \\
\text { mon board in production center } j\end{array}$ & $\mathrm{ch}_{s t^{\prime}}^{d / e}$ & $\begin{array}{l}\text { Unit cost of holding and handling } \\
\text { high/low-price certain elements which are } \\
\text { purchased at period } s \text { and consumed at } \\
\text { period } t^{\prime}\end{array}$ \\
\hline $\mathrm{ct}_{i j}^{c}$ & $\begin{array}{l}\text { Unit cost for transporting common parts } \\
\text { from supplier } i \text { to production center } j\end{array}$ & $c_{i^{\prime}}^{d / e}$ & $\begin{array}{l}\text { Unit cost of purchasing high/low-price el- } \\
\text { ements from supplier } i^{\prime}\end{array}$ \\
\hline $\mathrm{ct}_{j k}^{C}$ & $\begin{array}{l}\text { Unit cost for transporting common boards } \\
\text { from production center } j \text { to assembly cen- } \\
\text { ter }\end{array}$ & $\mathrm{ct}_{i^{\prime}}^{d / e}$ & $\begin{array}{l}\text { Unit cost of transporting high/low-price el- } \\
\text { ements from supplier } i^{\prime} \text { to assembly center }\end{array}$ \\
\hline $\operatorname{ch}_{j r}^{c}$ & $\begin{array}{l}\text { Unit cost for holding common part } r \text { in the } \\
\text { production center } j\end{array}$ & $\mathrm{cp}_{g}^{\mathrm{H} / \mathrm{L}-\mathrm{In}}$ & $\begin{array}{l}\text { Unit cost of assembling high/low-end prod- } \\
\text { uct } g\end{array}$ \\
\hline$\gamma_{g / r}^{C}$ & $\begin{array}{l}\text { Usage rate of common board/part } r \text { in } \\
\text { assembling innovative product } g / \text { common } \\
\text { board }\end{array}$ & $\operatorname{ch}^{C}$ & $\begin{array}{l}\text { Unit cost of holding and handling common } \\
\text { boards in the assembly center }\end{array}$ \\
\hline $\operatorname{dem}_{g m t}^{\mathrm{In}}$ & $\begin{array}{l}\text { Predicted demand of final innovative prod- } \\
\text { uct } g \text { in period } t\end{array}$ & $c_{g m}^{d, e} / c_{g m}^{e, d}$ & $\begin{array}{l}\text { Unit penalty cost resulted by substituting } \\
\text { high/low-end innovative product } g \text { instead } \\
\text { of low/high-end product } g \text { ordered by cus- } \\
\text { tomer } m\end{array}$ \\
\hline$\gamma_{r}^{F}$ & $\begin{array}{l}\text { Usage rate of part } r \text { in assembling func- } \\
\text { tional product } f\end{array}$ & $\mathrm{pn}_{g m}^{\mathrm{L} / \mathrm{H}-\mathrm{In}}$ & $\begin{array}{l}\text { Lost penalty for low/high-end product } g \\
\text { demanded by customer } m\end{array}$ \\
\hline $\mathrm{SC}_{i r}^{C_{\text {_Max }} / \mathrm{Min}}$ & $\begin{array}{l}\text { Maximum/minimum available part } r \text { for } \\
\text { supplying by supplier } i\end{array}$ & $\operatorname{pr}_{g}^{\mathrm{H} / \mathrm{L}}$ & The cost price of high/low-end product $g$ \\
\hline$u v_{r}^{C}$ & Required space to store common part $r$ & $\mathrm{util}_{g m}^{\mathrm{H} / \mathrm{L}}$ & $\begin{array}{l}\text { Utility measure of innovative high/low-end } \\
\text { product } g \text { for customer } m\end{array}$ \\
\hline $\mathrm{WS}_{j}^{\mathrm{L}}$ & Available space in production center $j$ & $D_{g m t^{\prime}}^{\mathrm{H} / \mathrm{L}-\mathrm{In}}$ & $\begin{array}{l}\text { Demand of customer zone } m \text { for high/low- } \\
\text { end product } g \text { at period } t^{\prime}\end{array}$ \\
\hline $\mathrm{Ss}_{j r t}^{C}$ & $\begin{array}{l}\text { Required safety stock of part } r \text { in produc- } \\
\text { tion center } j \text { at period } t\end{array}$ & $\xi^{d, e}$ & $\begin{array}{l}\text { The substitution incident matrix between } \\
\text { high and low-price elements }\end{array}$ \\
\hline$\overline{\mathrm{DT}}_{r}^{C}$ & $\begin{array}{l}\text { Maximum allowable delivery time for part } \\
r \text { delivered by suppliers }\end{array}$ & $\phi_{s t^{\prime}}^{d / e}$ & $\begin{array}{l}\text { growth exponential coefficient for obsoles- } \\
\text { cence cost regarding to the number of ob- } \\
\text { solesced periods }\end{array}$ \\
\hline $\mathrm{FcA}_{i^{\prime}}$ & $\begin{array}{l}\text { Fixed cost of alliance between the company } \\
\text { and supplier } i^{\prime}\end{array}$ & $\mathrm{Cap}_{g}^{\mathrm{In}}$ & $\begin{array}{l}\text { Capacity of assembling innovative product } \\
g\end{array}$ \\
\hline \multicolumn{4}{|c|}{ Decision variables } \\
\hline$O_{i r t}$ & $\begin{array}{l}1 \text {, if supplier } i \text { is selected to supply part } r \\
\text { at period } t \text {, and } 0 \text { otherwise }\end{array}$ & $x_{i^{\prime} s}^{d, e}$ & $\begin{array}{l}\text { Purchased quantity of high/low-price ele- } \\
\text { ments from supplier } i^{\prime} \text { a period } s\end{array}$ \\
\hline$X_{i j r t}^{C}$ & $\begin{array}{l}\text { Quantity of common parts } r \text { shipped from } \\
\text { supplier } r \text { to production center } j \text { at period } \\
t\end{array}$ & $Z_{g m t^{\prime}}^{\mathrm{H} / \mathrm{L}-\mathrm{In}}$ & $\begin{array}{l}\text { Quantity of high/low-end product } g \\
\text { shipped to customer zone } m \text { at period } t^{\prime}\end{array}$ \\
\hline$Y_{j f t}^{F}$ & $\begin{array}{l}\text { Quantity of functional products } f \text { shipped } \\
\text { from production center } j \text { to assembly cen- } \\
\text { ter at period } t\end{array}$ & $I_{t^{\prime}}^{C}$ & $\begin{array}{l}\text { Inventory level of common boards in as- } \\
\text { sembly center at period } t^{\prime}\end{array}$ \\
\hline$Y_{j t}^{C}$ & $\begin{array}{l}\text { Quantity of common boards shipped from } \\
\text { production center } j \text { to assembly center at } \\
\text { period } t\end{array}$ & $S_{t^{\prime}}^{d, e}$ & $\begin{array}{l}\text { Substituted quantity of high-price ele- } \\
\text { ments instead of low-price ones at period } \\
t^{\prime}\end{array}$ \\
\hline$I_{j r t}^{C}$ & $\begin{array}{l}\text { Inventory level of part } r \text { in production cen- } \\
\text { ter } j \text { at period } t\end{array}$ & $V_{g m t^{\prime}}^{\mathrm{L} / \mathrm{H}-\mathrm{In}}$ & $\begin{array}{l}\text { The loss of sale quantity of low/high-end } \\
\text { product } g \text { in customer zone } m \text { at period } t^{\prime}\end{array}$ \\
\hline$I_{s t^{\prime}}^{e / d}$ & $\begin{array}{l}\text { Inventory level of high/low-price elements } \\
\text { in assembly center purchased at period } s \\
\text { and consumed at period } t^{\prime}\end{array}$ & $\mathrm{AL}_{i^{\prime}}$ & $\begin{array}{l}1 \text {, if contract is set between company and } \\
\text { supplier } i^{\prime} \text {, and } 0 \text { otherwise }\end{array}$ \\
\hline
\end{tabular}




\section{REFERENCES}

[1] S. Aghamohammadi-Bosjin, M. Rabbani and R. Tavakkoli-Moghaddam, Agile two-stage lot-sizing and scheduling problem with reliability, customer satisfaction and behaviour under uncertainty: a hybrid metaheuristic algorithm. Eng. Optim. 52 (2020) 1-21.

[2] R. Babazadeh, J. Razmi and R. Ghodsi, Supply chain network design problem for a new market opportunity in an agile manufacturing system. J. Ind. Eng. Int. 8 (2012) 19-27.

[3] B. Beemsterboer, M. Land and R. Teunter, Hybrid MTO-MTS production planning: an explorative study. Eur. J. Oper. Res. 248 (2016) 453-461.

[4] B. Beemsterboer, M. Land and R. Teunter, Flexible lot sizing in hybrid make-to-order/make-to-stock production planning. Eur. J. Oper. Res. 260 (2017) 1014-1023.

[5] A. Ben-Tal, L. El-Ghaoui and A. Nemirovski, Robust Optimization. Princeton University Press, Princeton, NJ (2009).

[6] X. Brusset, Does supply chain visibility enhance agility? Int. J. Prod. Econ. 171 (2016) 46-59.

[7] H. Carvalho, S. Azevedo and V. Cruz-Machado, Agile and resilient approaches to supply chain management: influence on performance and competitiveness. Logist. Res. 4 (2012) 49-62.

[8] F. Chan and A. Kumar, Performance optimization of a leagility inspired supply chain model: a CFGTSA algorithm based approach. Int. J. Prod. Res. 47 (2009) 777-799.

[9] M. Ding, W. Ross and V. Rao, Price as an indicator of quality: implications for utility and demand functions. J. Retail. 86 (2010) 69-84.

[10] M. El Mokadem, The classification of supplier selection criteria with respect to lean or agile manufacturing strategies. J. Manuf. Technol. Manage. 28 (2017) 232-249.

[11] A. Faiza, Significance of lean, agile and leagile decoupling point in supply chain management. J. Econ. Behav. Stud. 3 (2011) 287-295.

[12] B. Giri, C. Mondal and T. Maiti, Optimal product quality and pricing strategy for a two-period closed-loop supply chain with retailer variable markup. RAIRO: OR 53 (2019) 609-626.

[13] R. Gössinger and S. Kalkowski, Robust order promising with anticipated customer response. Int. J. Prod. Econ. 170 (2015) $529-542$.

[14] A. Hasani, S. Zegordi and E. Nikbakhsh, Robust closed-loop supply chain network design for perishable goods in agile manufacturing under uncertainty. Int. J. Prod. Res. 50 (2012) 4649-4669.

[15] A. Haq and V. Boddu, Analysis of enablers for the implementation of leagile supply chain management using an integrated fuzzy QFD approach. J. Intell. Manuf. 28 (2017) 1-12.

[16] S. Hum, M. Parlar and Y. Zhou, Measurement and optimization of responsiveness in supply chain networks with queueing structures. Eur. J. Oper. Res. 264 (2018) 106-118.

[17] M. Inuiguchi and J. Rami, Possibilistic linear programming: a brief review of fuzzy mathematical programming and a comparison with stochastic programming in portfolio selection problem. Fuzzy Sets Syst. 111 (2000) 3-28.

[18] A. Jakubovskis, Flexible production resources and capacity utilization rates: a robust optimization perspective. Int. J. Prod. Econ. 189 (2017) 77-85.

[19] M. Khan, M. Hussain and L. Cárdenas-Barrón, Learning and screening errors in an EPQ inventory model for supply chains with stochastic lead time demands. Int. J. Prod. Res. 55 (2017) 4816-4832.

[20] H. Li and K. Womer, Optimizing the supply chain configuration for make-to-order manufacturing. Eur. J. Oper. Res. 221 (2012) 118-128.

[21] S. Liao, C. Hsieh and W. Ho, Multi-objective evolutionary approach for supply chain network design problem within online customer consideration. RAIRO: OR 51 (2017) 135-155.

[22] M. Lim, H. Mak and Z. Shen, Agility and proximity considerations in supply chain design. Manage. Sci. 63 (2016) $1026-1041$.

[23] C. Lin and T.H. Wang, Build to order supply chain network design under supply and demand uncertainties. Trans. Res. B: Meth. 45 (2011) 1162-1176.

[24] B. Liu and Y. Liu, Expected value of fuzzy variable and fuzzy expected value models. IEEE Trans. Fuzzy Syst. 10 (2002) 445-450.

[25] Y. Liu, H. Dong, N. Lohse and S. Petrovic, A multi-objective genetic algorithm for nalyzingon of energy consumption and shop floor production performance. Int. J. Prod. Econ. 179 (2016) 259-272.

[26] A. Lyons and A. Ma'aram, An examination of multi-tier supply chain strategy alignment in the food industry. Int. J. Prod. Res. 52 (2014) 1911-1925.

[27] M. Naim and J. Gosling, On leanness, agility and leagile supply chains. Int. J. Prod. Econ. 131 (2011) 342-354.

[28] P. Nieuwenhuis and E. Katsifou, More sustainable automotive production through understanding decoupling points in leagile manufacturing. J. Clean. Prod. 95 (2015) 232-241.

[29] F. Pan and R. Nagi, Robust supply chain design under uncertain demand in agile manufacturing. Comput. Oper. Res. 37 (2010) 668-683.

[30] D. Peidro, J. Mula, R. Poler and J.L. Verdegay, Fuzzy optimization for supply chain planning under supply, demand and process uncertainties. Fuzzy Sets Syst. 160 (2009) 2640-2657.

[31] M. Pishvaee, M. Rabbani and S. Torabi, A robust optimization approach to closed-loop supply chain network design under uncertainty. Appl. Math. Model. 35 (2011) 637-649. 
[32] M. Pishvaee, J. Razmi and S. Torabi, Robust possibilistic programming for socially responsible supply chain network design: a new approach. Fuzzy Sets Syst. 206 (2012) 1-20.

[33] S. Raj, S. Sundeer, Vinodha and G. Anandc, A mathematical model to evaluate the role of agility enablers and criteria in a manufacturing environment. Int. J. Prod. Res. 51 (2013) 5971-5981.

[34] U. Sağlam and A. Banerjee, Integrated multiproduct batch production and truck shipment scheduling under different shipping policies. Omega 74 (2018) 70-81.

[35] M. Seliaman, M. Khan and L. Cárdenas-Barrón, Algebraic modelling of a two level supply chain with defective items. RAIRO: OR 52 (2018) 415-427.

[36] A. Taleizadeh, S. Hadadpour, L. Cárdenas-Barrón, and A. Shaikh, Warranty and price optimization in a competitive duopoly supply chain with parallel importation. Int. J. Prod. Econ. 185 (2017) 76-88.

[37] S. Torabi and E. Hassini, An interactive possibilistic programming approach for multiple objective supply chain master planning. Fuzzy Sets Syst. 159 (2008) 193-214.

[38] S. Vinodh and S. Aravindraj, Evaluation of leagility in supply chains using fuzzy logic approach. Int. J. Prod. Res. 51 (2013) 1186-1195.

[39] B. Yan, J. Wu, L. Liu and Q. Chen, Inventory management models in cluster supply chains based on system dynamics. RAIRO: OR 51 (2017) 763-778.

[40] A. Yimer and K. Demirli, A genetic approach to two-phase optimization of dynamic supply chain scheduling. Comput. Ind. Eng. 58 (2010) 411-422.

[41] Y. Zhang, Y. Wang and L. Wu, Research on demand-driven leagile supply chain operation model: a simulation based on anylogic in system engineering. Syst. Eng. Proc. 3 (2012) 249-258. 